\title{
Removal of metal ions using Chitosan based electro spun nanofibers: A review
}

\author{
Texin Joseph ${ }^{1}$, Meera Jacob ${ }^{1}$, Veena R. Nair ${ }^{2}$, Jaya T. Varkey ${ }^{3}$ \\ ${ }^{1}$ Department of Chemistry, St. Pauls College, Kalamassery-683053, Kerala, India \\ ${ }^{2}$ Department of Chemistry, The Cochin College, Kochi-682002, Kerala, India \\ ${ }^{3}$ Department of Chemistry, St. Teresa's College. Ernakulam- 682035, Kerala, India \\ texin@stpauls.ac.in,meera@stpauls.ac.in, jayavarkey@yahoo.com, veenamk2004@gmail.com
}

DOI 10.17586/2220-8054-2021-12-6-728-748

\begin{abstract}
Chitosan is a promising environmentally-friendly polymer with a wide range of applications in biological, medical and water treatment fields. Recent research in chitosan-based electro spun nanofibers has led to the very cost-effective and efficient removal of toxic metal ions from solutions that are extremely important in today's pollution-ridden world. Nanofiber fabrication of chitosan blends can easily be done by the novel electrospinning technique. Because of their high adsorption capability, metal chelation ability, nontoxicity, biocompatibility, biodegradability, hydrophilicity, and cost effectiveness, chitosan-based nanofibers have seen rapid growth in water treatment applications. This review outlines the ability of electrospinning produced chitosan-based nanofibers to remove toxic metals. The primary goal of this review is to provide current information on various chitosan blend nanofibers that may be useful in water purification, as well as to encourage further research in this area.
\end{abstract}

Keywords: Chitosan, electrospinning, nanofibers, toxic metal removal, water purification.

Received: 4 July 2021

Revised: 30 October 2021

\section{Introduction}

Chitosan is a novel biomolecule which is biodegradable and bio-compatible. This polysaccharide is obtained by the deacetylation of chitin which is the major constituent of the exoskeleton of water-borne crustaceans [1]. Chitosan is a versatile and promising biomaterial [2]. The cationic nature of this polymer has attracted interest for a number of purposes and is the only abundant aminated polysaccharides which are available [3-6]. Chitosan is the $N$-deacetylated derivative of chitin, but this $N$-deacetylation is never complete. A rigid nomenclature with regards to the degree of $N$-deacetylation has not been defined between chitin and chitosan. About $6.89 \%$ of nitrogen is present in chitin and chitosan this is the reason why these materials are used as a chelating agent and have many commercial applications $[7,8]$. Consequently, chitosan has attracted tremendous attention for the creation of novel functional materials and potentially important renewable agricultural resource, and has been widely applied in the fields of agriculture, medicine, pharmaceuticals, cosmetic, food industries, environmental protection, and biotechnology (see Fig. 1). Recently [9], the chitosan backbone has had an increased capacity of adsorption due to the presence of a large number of amine groups [10-12].

Several physical and chemical methods have been used to modify raw flaked chitosan [13,14]. Physical modifications may increase the sorption properties; gel formation decreases the crystallinity of the sorbent and involves in an expansion of the porous network [15]. Chemical modifications also offer a wide spectrum of tools to enhance the sorption properties of chitosan for metals. Both hydroxyl and amine groups of chitosan can be chemically modified. They may increase the chemical stability of the sorbent in acidic media but decreases the solubility in most mineral and organic acids. They also increase its resistance to biochemical and microbiological degradation $[13,16]$. The physical and mechanical properties can be improved by cross-linking with glutaraldehyde [17-19], sulfuric acid [20], epoxides [21] and di-aldehyde starch [22]. Glutaraldehyde has been frequently used to cross-link chitosan. To stabilize the crosslinking of the chitosan in acidic solutions, a Schiff's base reaction between aldehyde groups of glutaraldehyde and some amine groups of chitosan were commonly used. It has been noted that cross-linking may reduce the adsorption capacity; it enhances the resistance of chitosan against acid, alkali and chemicals. The chemically modified chitosan has a great future and its development is practically limitless.

\subsection{Electrospinning}

For the fabrication of submicron-sized polymer nanofibers ranging from 5 to $500 \mathrm{~nm}$, electrospinning has been recognized as an effective technique. The nanofibers thus formed from the electrospinning process may be 100 times smaller than those prepared by traditional methods of solution or melt spinning [23]. The uniaxial stretching of a viscoelastic solution is used for the preparation of nanofibers through electrospinning. The principles of electrospinning and the different parameters that affect the processes have to be considered to understand and appreciate the 


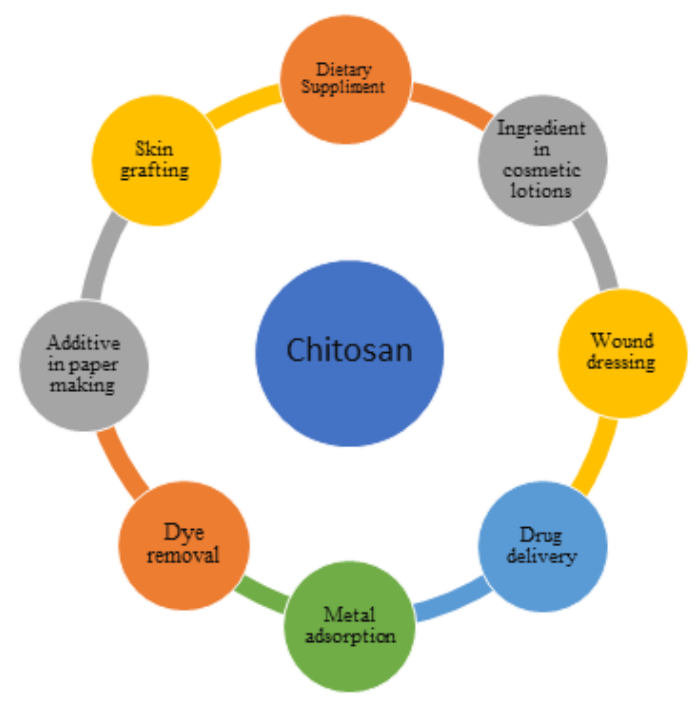

FIG. 1. Applications of chitosan

process which enables the formation of various nanofiber assemblies. For the solidification of the solution, electrospinning makes use of electrostatic forces [24]. An electric field is applied between the collector and the capillary end so that surface charge is induced on a polymeric fluid, deforming a spherical pendant droplet to a conical shape in an electrospinning process [25]. The charged fluid jet is ejected from the tip of the conical protrusion commonly referred to as Taylor cone. When the electric field surpasses a threshold value, the electrostatic repulsion forces of the surface charges overcome the surface tension and then the charge density on the jet interacts with the external field to produce instability. Large surface charge densities enhance a whipping mode rather than axisymmetric mode. Bending of the jet produces a highly stretched polymeric fiber with simultaneous rapid evaporation of the solvent. The main advantage of the electrospinning nano-manufacturing process is that it is cost effective compared to that of most bottom-up methods. The nanofibers prepared from an electrospinning process are often uniform and continuous and do not require expensive purification, unlike sub-micrometer diameter whiskers, inorganic nanorods, and composite material reinforcement [26].

\subsection{Electrospinning arrangement}

A high voltage supplier, a capillary tube with a needle and a collecting screen are the three main components of a typical electrospinning setup [27]. Fig. 2 shows a typical electrospinning setup. A $6 \mathrm{kV}$ applied voltage is required for initiation of the electrospinning process. The collector and the syringe needle are kept at the proper distance one from the other. Metallic plates, aluminum foils and rotating drums can be used as target for the collection of nanofibers during the electrospinning process. The potential difference enables the surface tension to be overcome by the electrostatic forces of the polymeric solution ejected from the needle tip and the so called "Taylor cone" configuration [28]. This process shapes the polymeric solution into a jet of charged fluid that is electrostatically attracted by the collector. The solvent evaporates during this transit from the needle to the collector, allowing for the accumulation of dry fibers on it. It is possible to run the electrospinning process at a lower applied voltage when a grounded target is introduced nearer to the spinneret [29]. The widely used spinnerets included clip spinneret, tubeless spinneret, co-axial spinneret, and heating spinneret. Co-axial electrospinning can be used to produce materials having low spin ability [30] and by using multi jet spinneret, materials can be electro spun at low voltages [31].

\subsection{Adverse effects of heavy metals}

Ground water pollution originating from both natural and anthropogenic sources presents a serious threat to the environment. Natural pollution sources include mineral and metallic deposits in sedimentary rocks and the release by soil of various metal ions into the environment. Man-made activities like mining, plating, glass making, ceramics, and battery manufacturing also lead to a great increase in heavy metal contamination in water, causing an ongoing risk to the biosphere [32]. Metals such as arsenic, chromium, copper, iron, lead, mercury, nickel and zinc, which have high toxicities and non-biodegradable properties, pose problems to both the environment and living organisms [33, 34]. Heavy metals pollutants in water are always an issue, because they can cause serious ailments such as dehydration, 


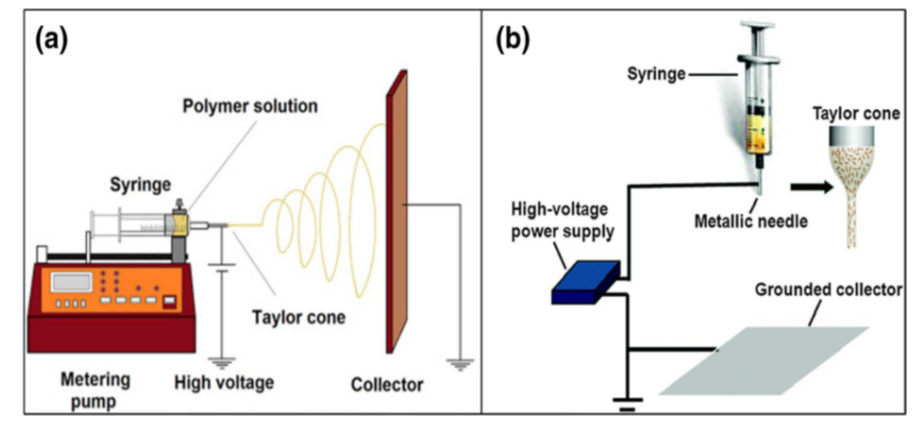

FIG. 2. Electrospinning arrangement (a) vertical; (b) horizontal [27]

stomach ache, nausea, and dizziness, lack of coordination in muscles, destruction of the nervous systems of young children, lung irritation, eye irritation, skin rashes, vomiting, lung insufficiency, and liver damage [35-37]. Many methods such as adsorption, electroplating, ion exchange, membrane separation, precipitation are being used to remove the ions of these metals from aqueous effluents [38-42]. Among these, adsorption is commonly regarded as an effective and economical method for wastewater treatment. Various types of adsorbents such as activated carbons [43-45], chitosan/ natural zeolites [46,47], biosorbents [48-50], and chelating materials [51,52] have been studied for the adsorption of metal ions from aqueous solutions. The adsorption properties of these adsorbents depend on the functional groups present on their surface. An adsorbent containing nitrogen-based ligands such as, amino, amidoxime, imidazole, and hydrazine groups was effective in forming complexes with metal ions [53-57].

In this work, the removal of metals like chromium, lead, copper, cadmium, thorium, uranium, mercury, nickel and arsenic from waste water by electro-spun nanofibers of chitosan, chitosan blends and modified chitosan were discussed.

\section{Removal of metal ions}

Heavy metal ions released into different water resources, are poisonous, carcinogenic, and pose a potential risk to human health and the atmosphere. Adsorption is one of the most effective techniques for removing heavy metal ions from aqueous solutions. Different kinds of adsorbents have been used to remove metal ions from various aqueous solutions, including activated charcoal, oxide crystals (ferric oxide, titanium oxide, cerium oxide, aluminium oxide, manganese oxide etc.), polymer fabrics, resins, and bio sorbents. In recent years, different natural fibers have drawn great interest as an adsorbent to remove heavy metal ions from wastewater due to their comparatively large exterior unique surface area. Metal ions in aqueous solutions can be transferred to the surface of the adsorbent by diffusion or convection, and then become bound to the surfaces due to various physical or chemical interactions between the metal ions and the adsorbent's surface functional groups. The formation of surface complexes, ion exchange, and chelation have all been proposed as effective adsorption mechanisms for heavy metal ions on various adsorbents. The amino group on an adsorbent, in particular, has been discovered to be one of the most important chelating groups for heavy metal ion adsorption. As a result, chitosan nanofibers produced via electrospinning with high adsorption potential for extracting heavy metal ions have piqued interest [58,59].

Yunpeng Huang et al. analyzed the heavy metal removal by electro-spun fibrous membrane, its mechanism and adsorption kinetics. The efficiency can be improved by surface group functionalization incorporation of nanoparticles. Electro-spun fibrous membranes outperform conventional adsorbents in a variety of ways, including higher permeation flux, lower pressure drops, flexible component adjustment, and multi-target adsorption [60]. Lei Zhang, et al. examined the various factors such as $\mathrm{pH}$, temperature, adsorbent dosage, contact time, and co-existing ions, which plays a key role in the metal removal. They also studied the adsorption kinetics, adsorption mechanism and furthermore, a response surface approach was used to optimize the process parameters of heavy metal adsorption by modified chitosan. Modified chitosan regeneration has received a lot of attention and several dynamic adsorption experiments have also been described [61]. Xin Rui, et al. investigated the role of electro-spun nanofibrous membranes in wastewater treatment. One of the primary issues associated is that the membrane with a nonwoven nanofibrous structure has very weak mechanical properties, which could limit its use in wastewater treatment. Different strategies and methodologies were investigated and discussed in this work, to improve the mechanical characteristics of nanofibrous membrane and ensuring the membrane's recyclability and reusability during the adsorption process [62]. Dhanush Gandavadi, et al. discussed in their work about bio-based nanofibers and their application in waste water treatment. They highlighted the use of biomaterials due to their ready availability, environmental friendliness aspects and resource efficiency. They 
also discussed various strategies like functionalization, incorporation of other natural and synthetic materials to improve the efficiency of nanofibers, which facilitates enhanced adsorption and the potential for removing heavy metal ions, dyes, and other contaminants polluting the environment [63].

\subsection{Chromium}

Chromium has been widely used in the pesticide industry, metallurgy, photography, corrosion control application, metal finishing, steel manufacture, paint formulations, leather industry, varnishes, dye industry, and textile industry, among others [64-66]. Chromium exists mainly in three oxidation states viz $+2,+3 \&+6$ [67]. Among the different states, $\mathrm{Cr}[\mathrm{VI}]$ is the most toxic one $[68,69]$. The presence of chromium in water is a serious threat to the human life and may cause severe health problems [70]. Different methods are used for the removal of chromium [VI] from aqueous solutions and these may include chemical precipitation, membrane filtration, ion exchange, and reverse osmosis [71, 72]. The production of large volumes of waste, requirement of high energy inputs, and high operating costs were some negative aspects of these methods $[73,74]$. Among the various techniques, adsorption is a very effective one which offers high efficiency, low cost, operational simplicity, versatility and the availability of a wide range of chemically and thermally stable adsorbents $[75,76]$. This method also has a broad applicability in water pollution control.

H. Behesthi et al. prepared, chitosan /multi-walled carbon nanotubes (MWCNT)/ $\mathrm{Fe}_{3} \mathrm{O}_{4}$ nanofiber for the effective removal of $\mathrm{Cr}(\mathrm{VI})$ from aqueous solutions. Chitosan powder is mixed with aqueous solution of $0.5 \mathrm{M}$ acetic acid for 24 hours at $300{ }^{\circ} \mathrm{C}$ using a magnetic stirrer. The prepared MWCNT/ $\mathrm{Fe}_{3} \mathrm{O}_{4}$ composite is stirred with the chitosan solution at room temperature for 6 hours. This composite solution is electro-spun to obtain a chitosan composite nanofiber. From the TEM image, it was clear that the nanofiber formed has a coaxial nanocable structure that had diameters of $\sim 10-15 \mathrm{~nm}$. The adsorption capacity of this nanofiber depends on the concentration of $\mathrm{MWCNT} / \mathrm{Fe}_{3} \mathrm{O}_{4}$, $\mathrm{pH}$, temperature and time. The maximum adsorption of $\mathrm{Cr}[\mathrm{VI}]$ ions has been occurred at a $\mathrm{pH}$ of 2 , temperature $45{ }^{\circ} \mathrm{C}$ and at an equilibrium time of 30 minutes. Kinetic studies show that the reaction follows a pseudo second order model. One of the advantages that can be pointed out is that the chitosan/MWCNTs/ $\mathrm{Fe}_{3} \mathrm{O}_{4}$ nanofibers can be reused without any frequent loss in adsorption [77]. G. Kummer, et al. prepared novel nanofiber materials composed of chitosan/nylon 6 by the force spinning method using formic acid as the solvent and it was used for the effective removal of chromium [VI] ions from aqueous solutions. The maximum adsorption capacity was $23.9 \mathrm{mg} / \mathrm{g}$. The kinetic studies shows that the reaction follows a pseudo second order model and the equilibrium isotherms best fit to the Langmuir model. The thermodynamic studies show that the adsorption was spontaneous, endothermic and favorable [78].

Liang Ma et al. developed core-shell-structured cellulose acetate-polycaprolactone/chitosan [CA-PCL/CS] nanofibers using coaxial electrospinning and reported an excellent removal performance of hexavalent chromium [Cr[VI]]. $10 \mathrm{~g}$ of chitosan was added to $\mathrm{N}, \mathrm{N}$-dimethylacetamide or acetone to obtain $10 \%$ solution. $1 \%$ cellulose acetate \& $15 \%$ poly caprolactone were dissolved in the formic acid or acetic acid by blending the solvent system to obtain polycaprolactone/cellulose acetatecomposite solution. The desired nanofiber cellulose acetate-polycaprolactone/chitosan as the shell components and chitosan as core were fabricated via coaxial electrospinning. It was noticed that the core shell structured fibers possess higher adsorption capability and good durability in acidic environment and also reported that CA-PCL/CS fibers with core-to-shell ratio of 0.442 have a maximum adsorption capability of $126 \mathrm{mg} / \mathrm{g}$ at room temperature. It is reported that it have a significant role in the adsorption of chromium [79].

Lei $\mathrm{Li}$ et al. reported the effective removal of chromium using chitosan nanofibers. Chitosan nanofibers were prepared using $90 \%$ acetic acid as the solvent by electrospinning. The $75 \mathrm{~nm}$ diameter chitosan nanofibers were cross-linked by glutaraldehyde vapor to minimize the material's solubility in aqueous solutions, and thus, the formed cross-linked chitosan nanofibers were good adsorbents of hexavalent chromium directly from aqueous samples The results showed a maximum adsorption capacity of about $131.58 \mathrm{mg} / \mathrm{g}$, which was more than double that of chitosan powder. It was also found that the adsorption is due to the presence of amino and the hydroxyl groups present in the chitosan [80].

Ehsan Bahmani et al. prepared the chitosan-grafted-poly [N-vinylcaprolactam][chitosan-g-PNVCL] nanofibers via electrospinning. ZIF-8 metal-organic frameworks nanoparticles were incorporated into the nanofibers for the adsorption of $\mathrm{Cr}[\mathrm{VI}]$ from water. The scanning electron microscope (SEM) image indicated an average particle size of $65 \mathrm{~nm}$ was fabricated for ZIF-8 metal organic frame works. The SEM image of the prepared nanofiber with shows an average diameter of $235 \mathrm{~nm}$. The effect of parameters on the Cr[VI] removal was studied. It is also found out that the synthesized nanofibers could be reused fora maximum of five sorption-desorption cycles.

The maximum experimental adsorption capacity of the chitosan-g-PNVCL/ZIF-8 nanofibers for Cr[VI] was $269.2 \mathrm{mg} / \mathrm{g}$ under ZIF-8 concentration of $3 \mathrm{wt}$. \%, adsorbent dosage of $0.5 \mathrm{~g} / \mathrm{L}$, pH of 3, equilibrium times of $30 \mathrm{~min}$, and temperature of $25^{\circ} \mathrm{C}$. 
A pseudo first order and Langmuir adsorption model was used to match the kinetic and equilibrium data of chromium adsorption. The obtained results showed that the prepared nanofiber loaded with ZIF- 8 had a high capacity for the removal of heavy metals [81].

Eryun Yan et al. synthesized the magnetic $\mathrm{Fe}_{3} \mathrm{O}_{4}$ containing polyvinyl alcohol/chitosan $\left[\mathrm{Fe}_{3} \mathrm{O}_{4} @ \mathrm{PVA} / \mathrm{CS}\right] \mathrm{com}-$ posite nanofibers via the electrospinning method and characterized by scanning electron microscope [SEM], transmission electron microscope [TEM], vibrating sample magnetometer [VSM] and Fourier transform infrared [FT-IR]. The prepared composite nanofibers were used as a novel adsorbent for removing toxic chromium [VI] from the aqueous solution. The doping of $\mathrm{Fe}_{3} \mathrm{O}_{4}$ nanoparticles [NPs] into the fibers had made a good effect on the absorption for Cr(VI) ions under both neutral and acidic conditions, and the saturated adsorption reached the maximum when $\mathrm{pH}$ was 3.0. The kinetics of $\mathrm{Cr}(\mathrm{VI})$ removal by the prepared composite nanofibers follows the pseudo-first-order model [82]. The possible adsorption mechanism is shown in Fig. 3.

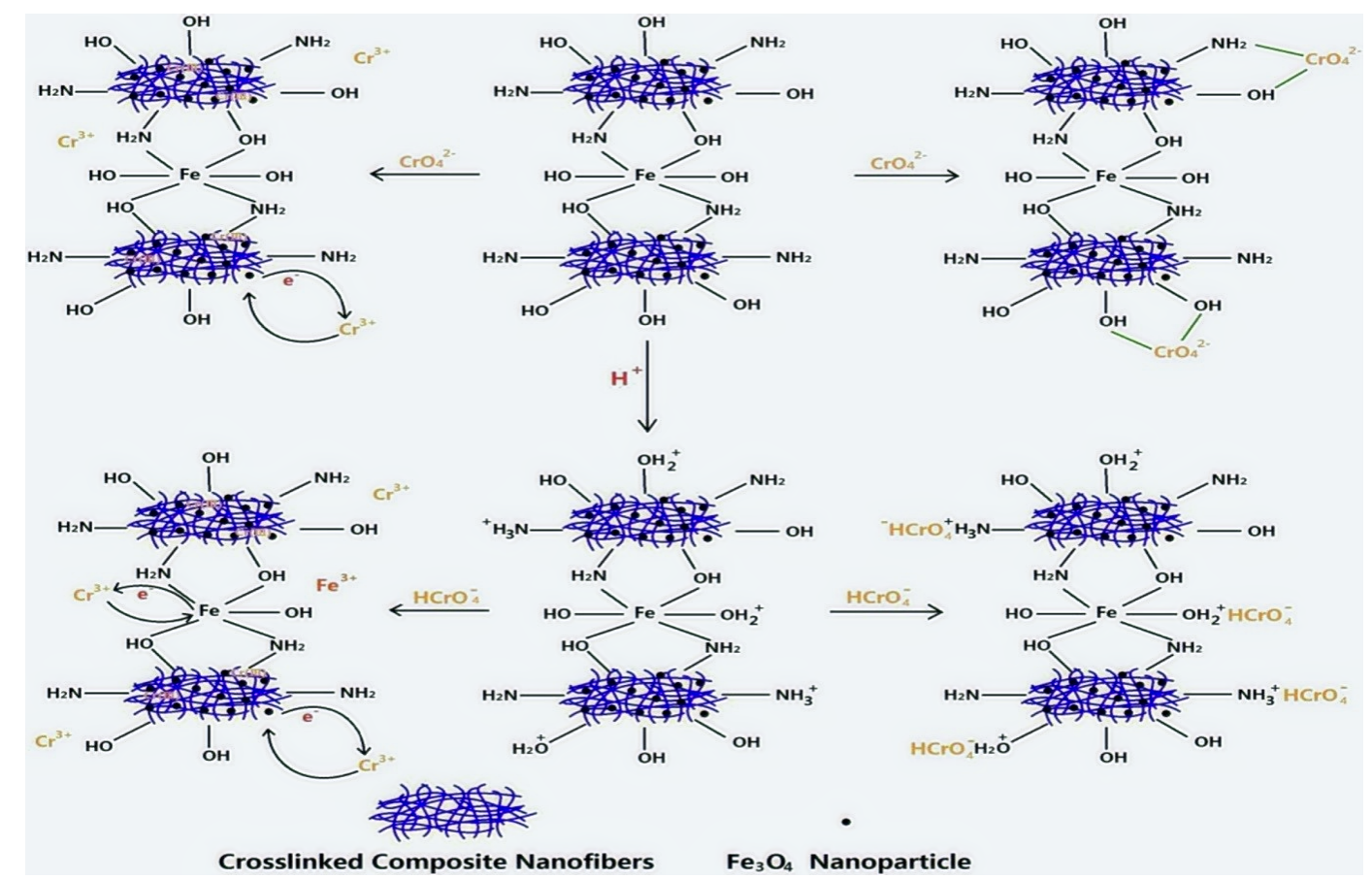

FIG. 3. The possible adsorption mechanism schematic diagram between $\mathrm{Cr}(\mathrm{VI})$ and the magnetic $\mathrm{Fe}_{3} \mathrm{O}_{4} @ \mathrm{PVA} / \mathrm{CS}$ composite nanofibers (Under neutral and acidic conditions) [82]

\subsection{Lead}

A major concern to the public health is the presence of heavy metal ions in water [83,84]. The main source of lead is the waste water from battery manufacturing factories. The industrial waste water containing lead ions is always a threat to the ecosystem. Evidence has shown that excess lead ions can cause a harmful effect both on ecological environment and human health [85-87]. Exposure resulting in acute lead poisoning may cause severe damage to the kidneys, liver, brain, and nervous system, and in addition, may induce sterility, abortion, and neonatal death [88]. From the previous studies, it is proved that adsorption process, due to its low cost and high efficiency is the most popular method for the removal of heavy metal ions $[89,90]$. As the nanofibrous adsorbent prepared by electrospinning process have high surface area and porosity, they have been widely used in adsorption of lead [91-97].

Adib Razzaz et al. prepared the chitosan/ $\mathrm{TiO}_{2}$ nanofiber by two different techniques - coating method and entrapped method. The adsorbing capacity of the nanofibers for the removal of $\mathrm{Pb}$ [II] was found to be $526.5 \mathrm{mg} / \mathrm{g}$ for the entrapping method and $475.5 \mathrm{mg} / \mathrm{g}$ for the coating method. It was also studied to determine if the chitosan/TiO nanofibers prepared by the entrapped method could be reused frequently without significant loss in adsorption performance after five adsorption/desorption cycles. Fig. 4 depicts the SEM images of chitosan/ $\mathrm{TiO}_{2} \mathrm{SEM}$ images. The kinetic and equilibrium studies had shown that it follows a pseudo first order kinetics and Redlich - Peterson isotherm model [98].

R. M. N Thumbi et al. proved that the $\mathrm{Pb}$ (II) removal by chitosan blend polyacrylamide nanofibers was accomplished without any additional synthetic modifications. They prepared the chitosan polyacrylamide blend solution 

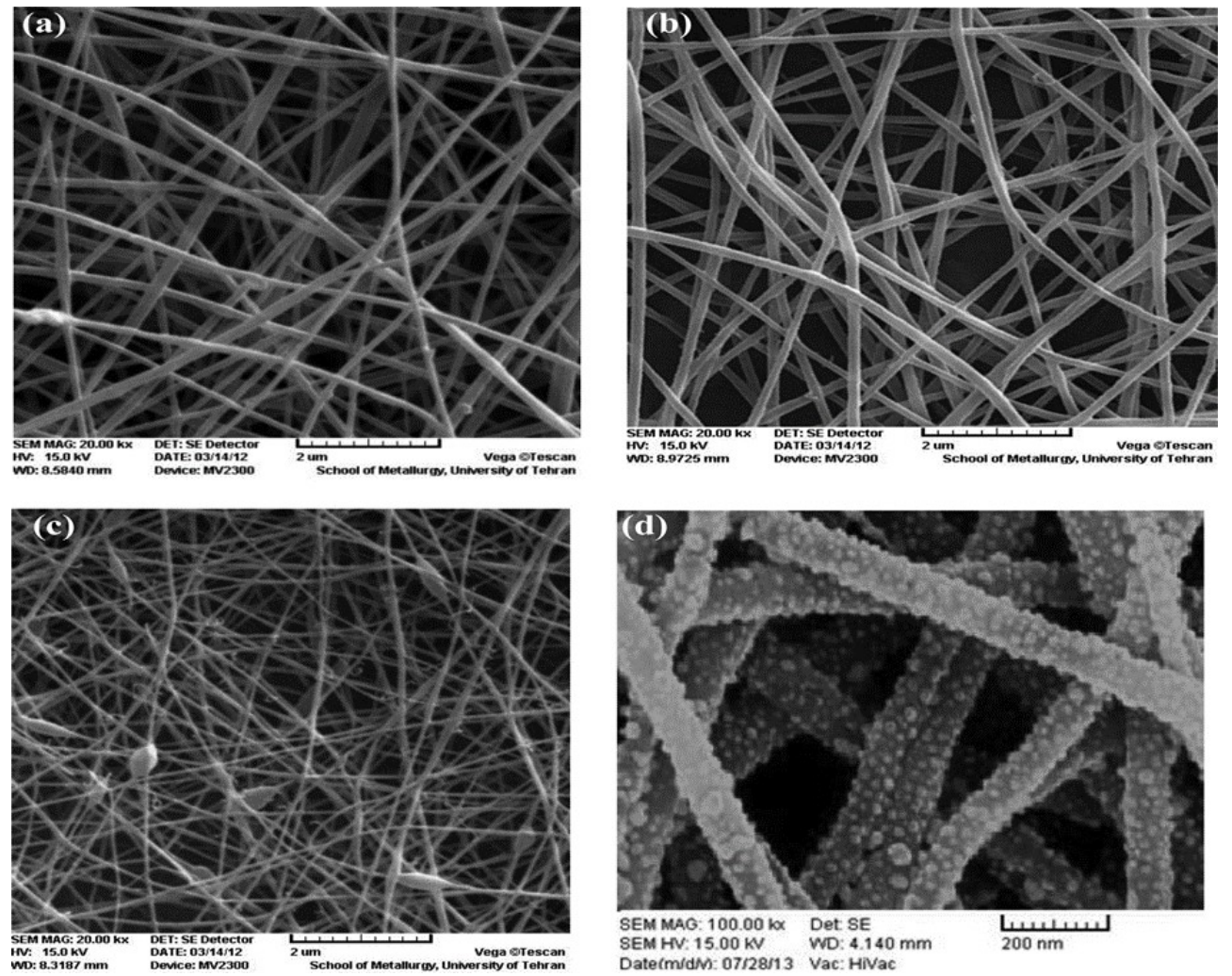

FIG. 4. SEM images of (a) chitosan; (b) chitosan/ $/ \mathrm{TiO}_{2} 2$ wt.\%; (c) chitosan/TiO 4 wt.\% and (d) $\mathrm{TiO}_{2}$ coated chitosan nanofibers [98]

by electrospinning method. The synthes is used aqueous solution of $0.52 \mathrm{M}$ acetic acid. The resultant nanofibers were crosslinked using glutaraldehyde as shown in Fig. 5. Parameters like different concentrations of acetic acid were taken for the optimization of the electrospinning parameters. The resulting solution is passed through the syringe to produce the electro-spun chitosan based nanofibers. The study reports show that the adsorption capacity for $\mathrm{Pb}$ was $56.54 \mathrm{mg} / \mathrm{g}$. The Freundlich isotherms explain the theory better than Langmuir. The resultant nanofibers were applied in the purification of both contaminated pond water and pulp waste. It was noticed that nanofiber prepared have removal efficiency of $100 \%$ in pond water; and $97.2 \%$ in pulp wastewater. The regeneration efficiencies [recovery \%] were $64 \%$ and $72 \%$ respectively [99].

Yan Li et al. prepared a novel and highly efficient lead ion-imprinted adsorbent of chitosan nanofiber mats. The electrospinning solution of chitosan with the lead chloride was prepared using trifluoroacetic acid $(\mathrm{TFA}) / \mathrm{CH}_{2} \mathrm{Cl} 2$ as the solvent. The nanofiber formed was crosslinked with glutaraldehyde. The results shows that the maximum adsorption for $\mathrm{Pb}[\mathrm{II}]$ ions was $577 \mathrm{mg} / \mathrm{g}$, which is five times more than that of the common chitosan-based adsorbents. The kinetic study proves that the adsorption of $\mathrm{Pb}[\mathrm{II}]$ ions follows a pseudo-second-order model [100].

Dong Wang et al. prepared a composite nanofibrous films using electrospinning technique and they modified the film by loading cellulose nanocrystals (CNC). The adsorption capacity of the films was studied by changing the CNC loading level, solution $\mathrm{pH}$, and adsorption time. The results showed that the adsorption of lead ions by the films was the best with CNC loading level of $5 \mathrm{wt} . \%, \mathrm{pH}$ of 6 , and adsorption time of $4 \mathrm{~h}$. The adsorption behavior of the films was agreed with the Freundlich model. The adsorption equation of metal ions could be described while using a pseudo-second order model. The maximum adsorption capacity of $\mathrm{Pb}[\mathrm{II}]$ ions was estimated as $323.49 \mathrm{mg} / \mathrm{g}$. The $\mathrm{Pb}[\mathrm{II}]$ ion adsorption efficiency of the films after 4 adsorption-desorption cycles was $90.21 \%$ [101].

Hossein Hadi et al. developed a novel electro-spun chitosan/graphene oxide [GO] nanofibrous adsorbent by electrospinning process. The adsorption behaviors of $\mathrm{Pb}^{2+}$ from aqueous solutions using chitosan/GO nanofibers were investigated. Kinetic and equilibrium studies showed that the experimental data of $\mathrm{Pb}^{2+}$ was best fitted with double-exponential model and Redlich - Peterson isotherm models. The maximum monolayer adsorption capacity of $\mathrm{Pb}^{2+}$ ions using chitosan/GO nanofibers was found to be $461.3 \mathrm{mg} / \mathrm{g}$ at an equilibrium time of $30 \mathrm{~min}$ and temperature of $45^{\circ} \mathrm{C}$. By the evaluation of the thermodynamic parameters, it was proved that the nature of the metal ions sorption by chitosan/GO nanofibers was endothermic and spontaneous. It is also noted that the chitosan/GO nanofibers could 


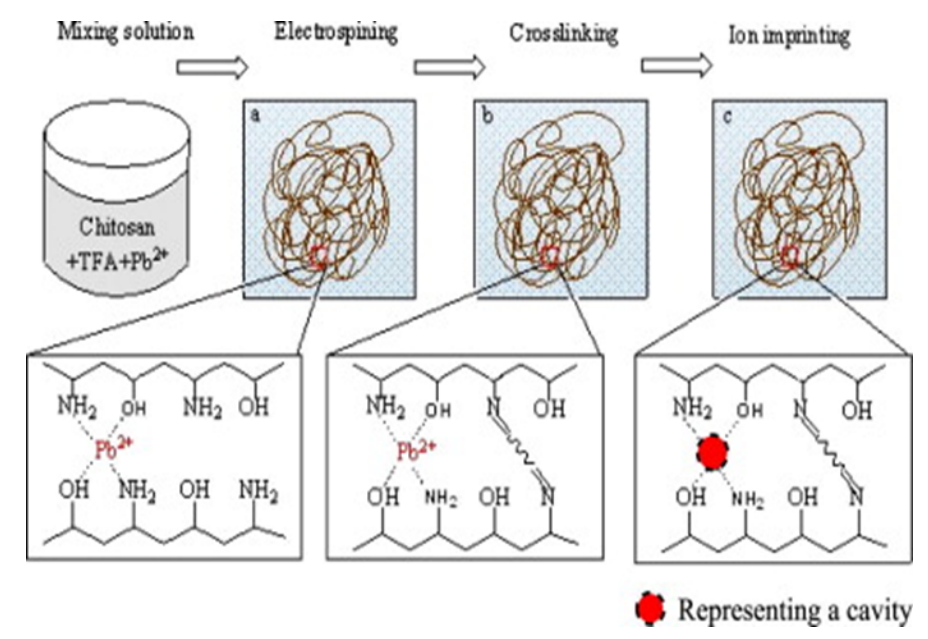

FIG. 5. Preparation of the lead-ion imprinted crosslinked electro-spun chitosan nanofiber mats [100]

be reused frequently without almost any significant loss in adsorption performance. This study provides a promising chitosan/GO nanofibrous adsorbent with a good adsorption property for heavy metal ions removal [102].

\subsection{Copper}

Water resources are extensively used in all stages of industrial production and consequently contaminated with heavy metal ions, which are often disposed into the environment. Heavy metal ions accumulate in living organisms as a result of their presence in drinking water, air, and soil, resulting in illnesses, poisoning, and mutations [103, 104]. Excess $\mathrm{Cu}^{2+}$ can cause some renal diseases, liver dysfunction, stroke, inflammation and cancer [105]. Therefore, environmental protection and remediation systems must be developed to eliminate pollution of this metal.

Natalia S. Surgutskaia et al. had prepared diethylenetriaminepentaaceticacid(DTPA)-modified chitosan [CSDTPA] for the effective of $\mathrm{Cu}^{2+}$ ions by ethylcarbodiimidehydrochloride/N-hydroxy-succinimide crosslinking [106]. The preparation was done by mixing around $10 \mathrm{ml}$ of $2 \%$ chitosan solution of $\mathrm{pH}$ about 4.7 and $10 \mathrm{ml}$ of DTPA solution which was activated with $\mathrm{N}$-hydroxy-succinimide and ethylcarbodiimide hydrochloride at $\mathrm{pH}$ 4.7. Nanofibre formation is clearly in Fig. 6. This modified chitosan nanofiber showed better adsorption of $\mathrm{Cu}^{2+}$ from aqueous solutions as shown in Fig. 7. The maximum adsorption shown by this nanofiber was $177 \mathrm{mg} / \mathrm{g}$ for $\mathrm{Cu}^{2+}$ ions [107].

Ichrak Lakhdar et al. reported the removal of copper from aqueous solutions using modified chitosan nanofibers with polyethylene oxide. The solution was prepared by mixing $4 \%$ wt chitosan in $50 \%$ acetic acid and $4 \%$ polyethylene oxide in $50 \%$ acetic acid for $18-24$ hours of ambient temperature and the $4 \%$ weight electro-spun chitosan nanofibers were produced using a horizontal electrospinning technique. The results show an adsorption of $94.7 \%$ of copper from the aqueous solutions. Kinetic studies have showed that the adsorption of copper ions on CS/PEO nanofibers follows a chemisorption by chelation mechanism. From the equilibrium studies, it was noted that the adsorbed copper forms a monolayer with equal distribution of the energy on the homogeneous surface of the adsorbent as seen in Fig. 8 [108].

Cardenas Bates et al. developed electro-spun chitosan-polyethylene oxide nanofiber mats using a new collector design. Continuous flawless nanofibers of $151 \pm 36 \mathrm{~nm}$ in diameter were achieved by this method. Adsorption capacity of the mats for copper ions in aqueous solutions was investigated. The results showed that sorption equilibrium was achieved within 2.5 hours with a homogenous distribution of copper ions within the nanofiber mats. Kinetic studies show that pseudo-second order kinetic model is best fitted the experimental data. The sorption processes are best described with the Langmuir isotherm with a maximum adsorption capacity of $124 \mathrm{mg} / \mathrm{g}$ for trial temperatures ranging from 25 to $60{ }^{\circ} \mathrm{C}$. Thermodynamic parameters $\left[\Delta G^{\circ}, \Delta H^{\circ}\right.$ and $\Delta S^{\circ}$ ] proved that the adsorption was feasible, endothermic and spontaneous. The results of desorption studies revealed that the electro-spun chitosan mats can be desorbed and reused up to 5 cycles without significant loss in adsorption performance [109].

Sajjad Haider et al. prepared chitosan nanofiber mat for the removal of copper from waste water. $3 \mathrm{wt} \%$ chitosan solutions were prepared in TFA and the nanofiber is prepared by electrospinning at $20 \mathrm{kV}$ voltage. The dried nanofiber mat was neutralized using potassium carbonate solution [M], and the mat was taken out from the aqueous solution, washed repeatedly with the deionized water until the $\mathrm{pH}$ of the solution become 7 and dried at about $600{ }^{\circ} \mathrm{C}$ for about 24 hours under vacuum. The freeze dried chitosan nanofiber mats prepared shows a high adsorption value for the metal ions and good erosion stability in water. Fig. 9 depicts the SEM images of nanofibres during the various stages. 

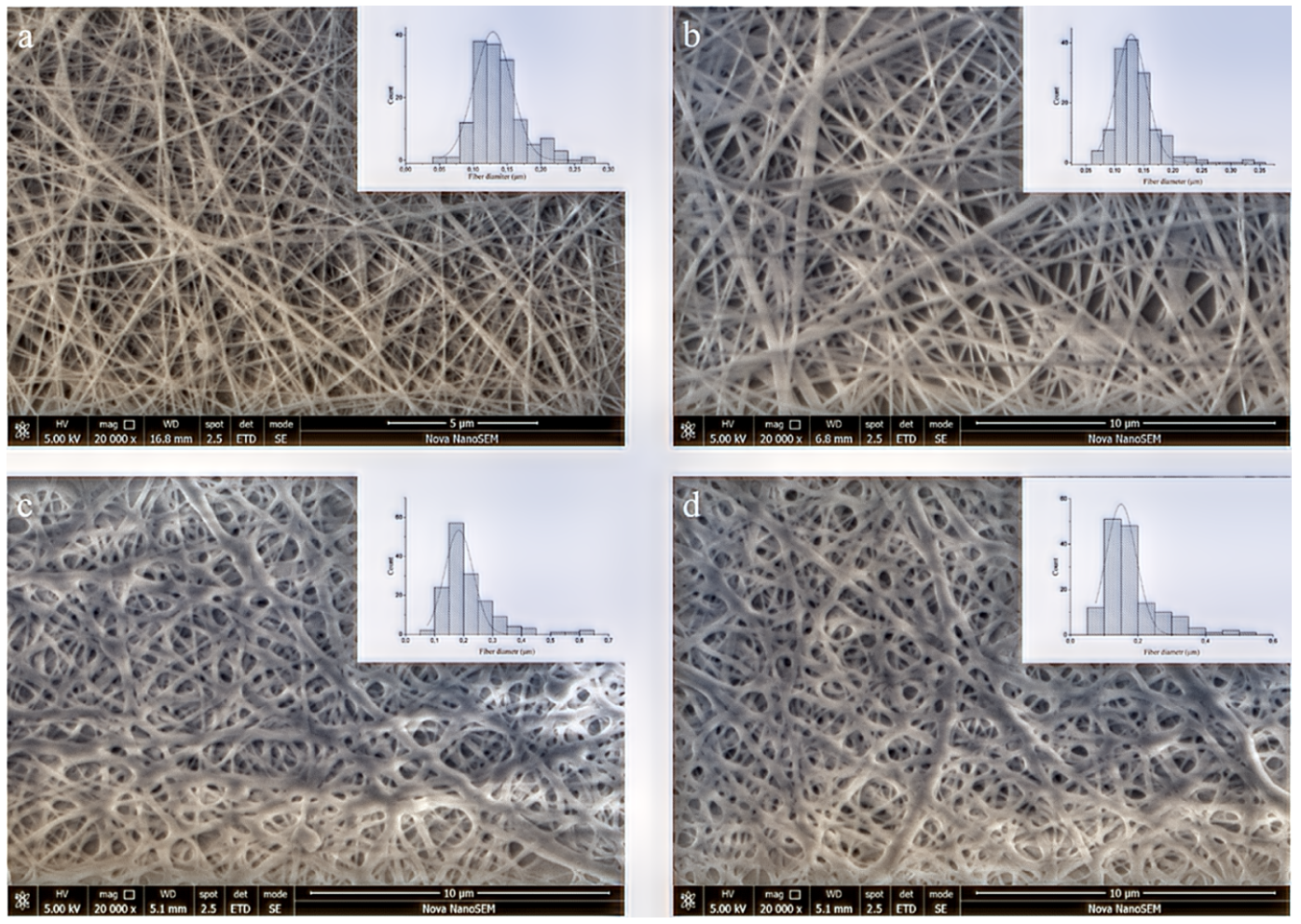

FIG. 6. SEM images and size distribution of pre- and post-stabilized CS/PEO (a,c) and CSDTPA/PEO (b,d) nanofibers [107]

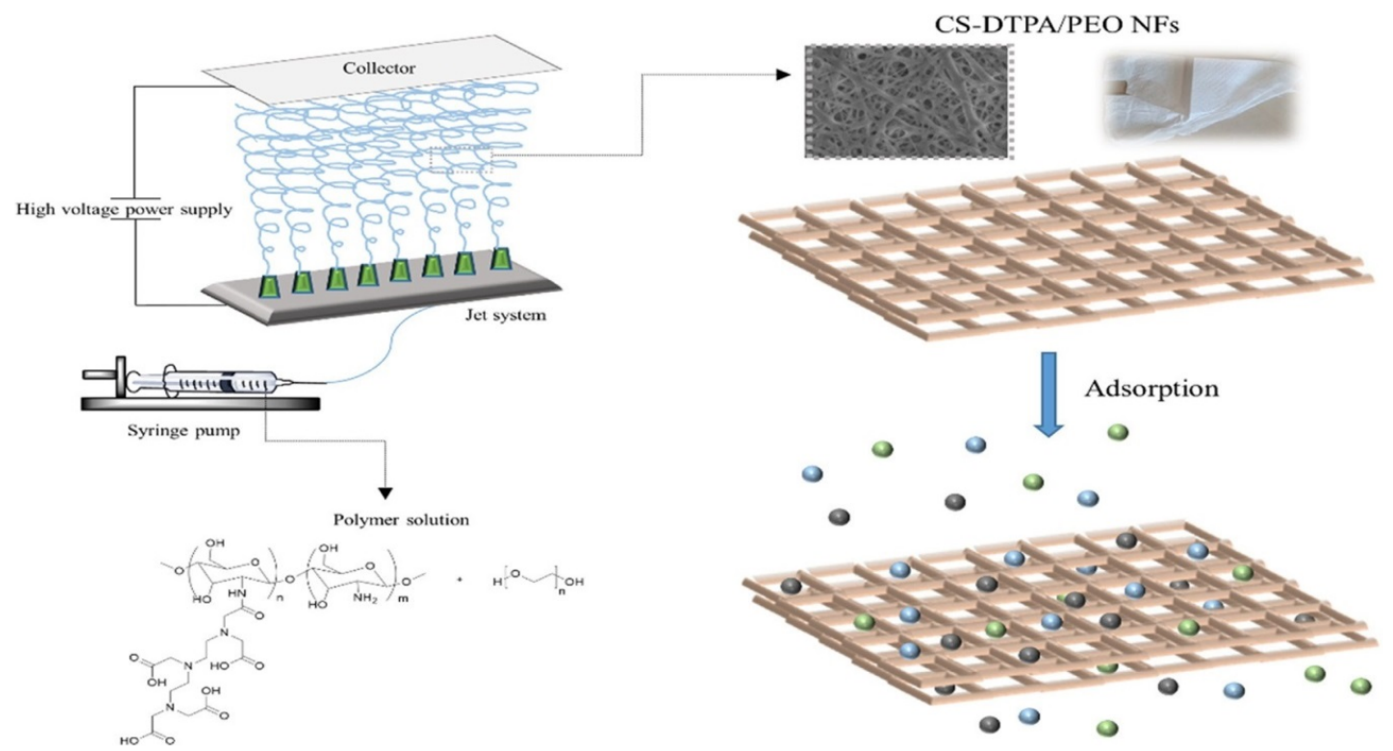

FIG. 7. Schematic illustration of preparation and adsorption properties of CS-DTPA/PEO NFs [107] 


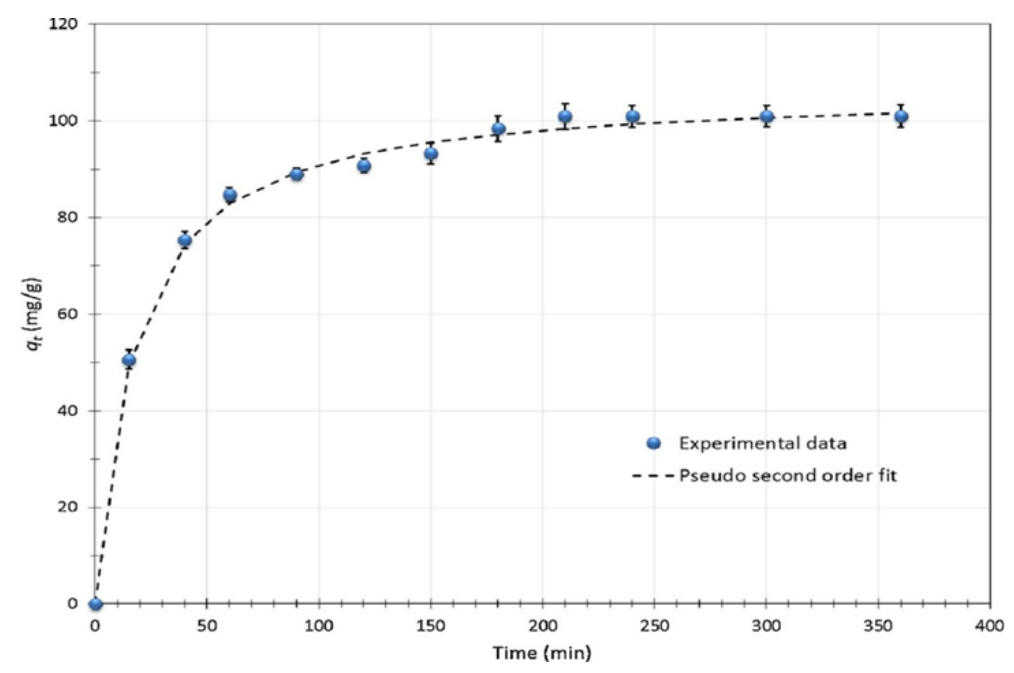

FIG. 8. Adsorption kinetic of copper ions by chitosan electro-spun nanofibers [108]
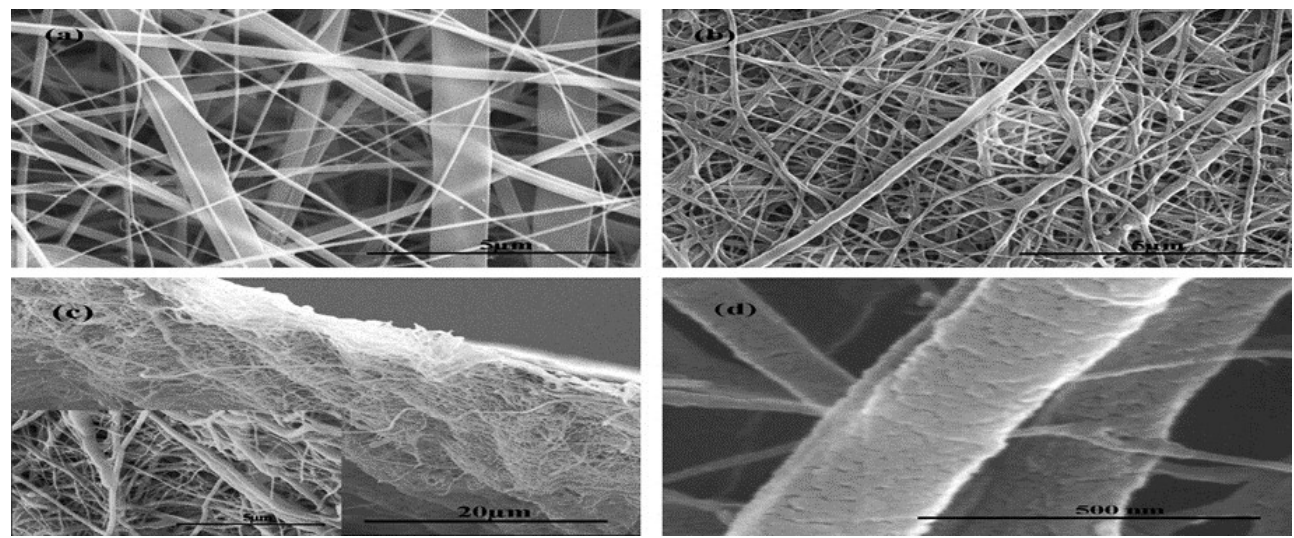

FIG. 9. FE-SEM micrographs of the chitosan nanofibers: (a) as-spun; (b) neutralized and (c) neutralized freeze-dried surfaces, and (d) enlarged nanofibers [110]

The results had showed that the equilibrium adsorption capacities for $\mathrm{Cu}[\mathrm{II}]$ were $485.44 \mathrm{mg} / \mathrm{g}$. It is reported that the $\mathrm{Cu}[\mathrm{II}]$ adsorption capacity of this fiber is 6 higher than any other methods. This high adsorption capacity was explained based on the high surface area per unit mass of nanofiber [110].

Dongxue Yang et al. studied how to improve the adsorption ability of chitosan [CS] for heavy metal ions. They prepared rich amino-functionalized CS electro-spun membranes. During the efficient synthesis, polyglycidyl methacrylate [PGMA] and polyethylenimine [PEI] were orderly grafted on the surface of CS electro-spun membrane. $\mathrm{X}$-ray diffractometer [XRD] analysis confirm the introduction of amino-group on the chitosan. The maximum adsorption capacity of $\mathrm{Cu}^{2+}$ by CS-PGMA-PEI was $69.27 \mathrm{mg} / \mathrm{g}$. It was noted that the adsorption equilibrium of the heavy metal ion solutions was rapidly established in $60 \mathrm{~min}$. The kinetics analysis revealed that the adsorption process of CSPGMA-PEI followed a pseudo-second-order and can be described by Langmuir model. The prepared CS-PGMA-PEI membrane also exhibited a good reproducibility and stability [111].

Josó Ortiz C et al. studied about how nanofibrous mats based on chitosan can be used for removal of copper [II] ions in aqueous solutions. They fabricated different nanofibers based on chitosan-electro-spun CS-PEO nanofibers, PVA nanofibers coated with chitosan, and PVA: PAA nanofibers coated with chitosan to compare their effectiveness in the adsorption of $\mathrm{Cu}^{2+}$ in aqueous solutions. Among the different types of nanofibers prepared, PVA: PAA nanofibers had the best shape and thickness in comparison with CS-PEO nanofibers and PVA nanofibers. Beads were present in all the electro-spun nanofibers but they were reduced with the control of viscosity and surface tension parameters. The maximum average percentage of adsorption for the different nanofibers is as follows - CS-PEO nanofibers were of $32 \%$. For CS-PVA Nanofibers, this value was $16 \%$, and finally, for CS-PVA: PAA nanofibers, the figure was $98 \%$. In conclusion, CS-PVA: PAA nanofibers had the best percentage of adsorption [112]. 
Qasim Zia et al. prepared porous poly L-lactic acid [PLLA] nanofibrous membrane with the high surface area by electrospinning method and post acetone treatment was used as a substrate for the deposition of chitosan. The porous PLLA/chitosan structure provided the chitosan with a high surface framework to fully and effectively adsorb heavy metal ions from water and showed higher and faster ion adsorption. The composite membrane was used to eliminate the copper ions from the aqueous solutions. Chitosan acts as an adsorbent due to the presence of the amino and hydroxide groups which are complexation sites for the capture of copper ions. The maximum adsorption capacity of copper ions was $111.66 \pm 3.22 \mathrm{mg} / \mathrm{g}$ at $\mathrm{pH} 7$ at an interaction time of $10 \mathrm{~min}$ and temperature about $25^{\circ} \mathrm{C}$. The adsorption kinetics of copper ions and was well agreed with the second-order model and adsorption studies follow Langmuir isotherm. From the thermodynamic studies it was found that the adsorption system was exoergic and spontaneous. From this study chitosan modified porous PLLA nanofiber can be proved as a green adsorbent for purification of aqueous solutions containing metal ions such as copper [113].

\subsection{Cadmium}

Nowadays, the removal of heavy metal pollutants such as cadmium from the wastewater is a serious issue because of their serious and detrimental effects both to the environment and human health [114,115]. Cd[II] ions are nonbiodegradable and poisonous. The main source of the cadmium metal are organic chemicals, cadmium-nickel battery, mining, pigments, stabilizers and other industries leading to the release of pollutants to the natural environment by long-range transport diffusion [116]. A number of technologies were applied to eliminate heavy metal ions from water streams containing solvent extraction precipitation, membrane, flotation, coagulation,ion exchange, and adsorption etc. Among these methods, adsorption is the most effective and cheapest one.

Alharbi H.F. et al. prepared nanofiber of PAN (Poly Acrylo Nitrile) doped with metal oxide and chitosan by electrospinning for the removal of cadmium. The work investigated the role of $\mathrm{pH}$, initial concentration, adsorption time were studied and established the influence of metal oxide doping $[\mathrm{ZnO}] / \mathrm{TiO}_{2}$. Introduction of chitosan to functionalized PAN enhances the adsorption of cadmium by four-fold. Kinetic studies review the pseudo-second order and Langmuir isotherm equation. The maximum adsorption capacity was found to be $160 \mathrm{mg} / \mathrm{g}$ for cadmium ion [117].

Ricardo Brandes et al., in their research for the removal of $\mathrm{Cd}[\mathrm{II}]$ ions from aqueous solution, developed a new nanofibrous electro-spun nonwoven sorbent made from chitosan [CS] and phosphorylated nanocellulose [PNC]. SEM, EDX, AFM and FTIR were used for characterizing the adsorbent material. The results show that adsorption capacity reached $62.3 \mathrm{mg} / \mathrm{g}$ at $\mathrm{pH} 5.5$ and $25{ }^{\circ} \mathrm{C}$. The $\mathrm{Cd}[\mathrm{II}]$ adsorption occurs at a rapid speed and achieved equilibrium within 120 minutes. Kinetic studies showed that the reaction fits a pseudo-second order kinetic model and the sorption isotherm was best described by the Langmuir adsorption isotherm. The maximum adsorption capacity of Langmuir was $232.55 \mathrm{mg} / \mathrm{g}$ at $25^{\circ} \mathrm{C}$, and increased with temperature, which can be explained by the high affinity of amine and phosphate groups with cadmium on the surface of the nanofibrous mats. The thermodynamic study showed that the adsorption follows a spontaneous endothermic reaction. This work also confirmed that an electro-spun nanofibrous mats based on CS and PNC can be used as an alternative material for the removal of cadmium ions, contributing to water sustainability [118].

Mohammad Rezaul Karim et al. synthesized nanofibers membranes which were fabricated by polyvinyl alcohol/chitosan [PVA/Chi] using an electrospinning technique for selective and high adsorption of cadmium Cd[II] ions based on the solution acidity. The adsorption capacity of this fiber was investigated against the parameters such as initial metal ions concentration, interaction time, adsorbent dosage and solution $\mathrm{pH}$ also were evaluated. The adsorption data fit towards the pseudo-second-order model for $\mathrm{Cd}[\mathrm{II}]$ ions and the equilibrium data were well fitted with the Langmuir adsorption isotherms model. The maximum adsorption capacity was $148.79 \mathrm{mg} / \mathrm{g}$ for Cd[II] ions. The $\mathrm{Cd}[\mathrm{II}]$ ions adsorptions were also measured to know the selectivity with simulated environmental solution, and the data shows the high selectivity for $\mathrm{Cd}[\mathrm{II}]$ ions at the optimum conditions. Thus, the PVA/Chi NFs are considered to be an effective and promising material for the removal of $\mathrm{Cd}[\mathrm{II}]$ ions from wastewaters with high efficiency [119].

Sana Jamshidifarda et al. prepared PAN/chitosan/UiO-66- $\mathrm{NH}_{2}$ nanofibers for adsorption and membrane filtration of $\mathrm{Cd}[\mathrm{II}]$ ions from aqueous solutions. UiO-66- $\mathrm{NH}_{2}$ MOF content [0 - 15 wt. \%], $\mathrm{pH}$ [2 - 7], contact time [5 $90 \mathrm{~min}]$, initial metal ion concentration $[20-1000 \mathrm{mg} / \mathrm{L}]$ and temperature $\left[25-45^{\circ} \mathrm{C}\right]$ have a marked influence on the adsorption capacity of the nanofiber. Kinetic studies follows a pseudo-second-order kinetic and Redlich Peterson isotherm model accurately described the experimental sorption data. At optimum conditions, UiO-66- $\mathrm{NH}_{2}$ the nanofibrous adsorbent for $\mathrm{Cd}[\mathrm{II}]$ ions sorption was found to be $415.6 \mathrm{mg} / \mathrm{g}$. It wasalso noted that an increase in the active layer thickness from 10 to $70 \mu \mathrm{m}$ and increased the MOF content in the membrane matrix from 0 to $10 \mathrm{wt} \%$ as well as initial concentration of metal ions from 5 to $50 \mathrm{mg} / \mathrm{L}$ resulted in increasing metal ions removal and decrease in the water flux. When the temperature was increased from 25 to $45^{\circ} \mathrm{C}$ it resulted in increasing the water flux and a slight decrease in the metal ion removal [120]. 
Merin S. Thomas et al., in their work, explained the fabrication of polylactic acid [PLA]/Nano chitosan [nCHS] composite fibers by electrospinning method for $\mathrm{Cd}^{2+}$ metal ion adsorption from water. Here, nCHS was synthesized by a method known as ionic gelation method. The scanning electron microscopic analysis revealed that the addition $0.1 \mathrm{wt} \% \mathrm{nCHS}$ has decreased the fiber diameter as well as the secondary pore size and hence imparted unique properties to electro-spun composite fibers. The composite nanofibers have higher stability, reduced crystallinity, higher hydrophilicity and high surface area compared to individual material. The basic character of the composites has intensified with the increase in nCHS addition was proved by inverse gas chromatography. $70 \% \mathrm{Cd}^{2+} \mathrm{removal}$ efficiency was achieved by this method [121].

\subsection{Mercury}

Mercury [II] is a highly reactive ion which binds to the amino acid cysteine in proteins. It is considered to be a carcinogen causing embryocidal, cytochemical, and histopathological events [122]. On converting into methylmercury, mercury and its compounds can affect the human beings even at very low concentrations [123, 124]. The main sources for contamination of water by mercury are wastewater discharges from industries like chlor-alkali, paper and pulp, oil refining, paint, pharmaceuticals and batteries. Various methods have been reported for removal of $\mathrm{Hg}$ [II], including chemical precipitation, ion exchange, membrane filtration, electrochemical separation, reverse osmosis, solvent extraction and adsorption [125-128].

Reena Sharma et al. prepared various combinations of Ce-PVA-CHT composite by electrospinning technique. From their experiments it has been noticed that from the various combinations, 7:3 ratio of PVA and CHT forms the bead free nanofibers. Homogenous solutions of $4 \mathrm{wt} \% \mathrm{CHT}$ powder in $2 \%$ [v/v] formic acid and 8 wt $\%$ PVA in $2 \%[\mathrm{v} / \mathrm{v}]$ acetic acid were prepared at room temperature. A desirable viscous solution of 7:3 ratio was prepared and mixed with cerium [III] nitrate hexahydrate [0.5 - 5.0 w/w \%] and was electro-spun at $20 \mathrm{kV}$ to form Ce-PVACHT composite nanofiber. Nanofibers were cured at $\sim 110{ }^{\circ} \mathrm{C}$ for 5 hours prior to its use for $\mathrm{Hg}[\mathrm{II}]$ adsorption studies. The main advantage of this polymer is that they are bio degradable, non-toxic and are of low cost. The results shows that the adsorption of PVA-CHT by Ce is around $31.44 \mathrm{mg} / \mathrm{g}$ and effective removal of $\mathrm{Hg}[\mathrm{II}]$ occurs at low to moderate concentrations. The adsorption of $\mathrm{Hg}[\mathrm{II}]$ on composite nanofibers may be due to the small ionic radii, high electric charge and high potential energy. Best results were observed at a $\mathrm{pH}$ range of 5.3 - 6.0. The kinetics studies showed that the adsorption process follows a pseudo second order and the Langmuir isotherm shows monolayer adsorption [129].

\subsection{Thorium}

Thorium [IV] is a radioactive fissionable metal ion, and the embodiment of its radioactive isotopes in living body over a period of time could cause several health hazards like neurotoxicity and other noxious diseases [130].

Prakash Macchindra Gore et al. prepared the chitosan/RTIL homogenous solution by dissolving $3 \%$ chitosan in $5 \%$ acetic acid and integrating to the $8 \%$ PVA solution and stirred for $2 \mathrm{~h}$ using a magnetic stirrer for about 2 hrs. Solutions of $0.5,1,2,3,4,5,10$ wt \% 1-butyl-3-methylimidazolium tetrafluoroborate [BMIM-BF4] are added to the chitosan to prepare Chitosan/RTIL mixture and the mixture is stirred for an hour. The precursor solution for electrospinning is prepared by adding $0.01 \mathrm{wt} \%$ of thorium nitrate to get the ion-imprinted solution. A $1000 \mathrm{ppm}$ solution of $\mathrm{Th}\left[\mathrm{NO}_{3}\right]_{4}$ in deionized water is used as the stock solution for the experiment. The influence of $\mathrm{pH}$, temperature, adsorption and time were studied for the effective removal of thorium by chitosan/RTIL fibers. The possible mechanism of thorium adsorption is shown in Fig. 11. The maximum adsorption efficiency was reported as $90 \%$ at a neutral $\mathrm{pH}$ of 7 , temperature of $298 \mathrm{~K}$ within 2 hours [131].

\subsection{Uranium}

Uranium is a naturally occurring, primordial and ubiquitous heavy metal. The main sources of uranium pollution are nuclear fuel industry, nuclear weapons, exploitation of ore deposits for the extraction, have increased the presence of $U$ in the environment. The element uranium can exhibit variable valences such as $+2,+3,+4,+5$ and +6 in nature; among these, the most common and stable form of uranium is $\mathrm{U}^{6+}$, which is soluble in water [132, 133]. Recently, uranium has become a serious concern because of its chemical toxicity and radioactivity, and thus, the removal and recovery of uranium from contaminated sites and aqueous systems is of particular interest. Several methods were used for this and some of the methods were chemical precipitation, solvent extraction, membrane separation, and adsorption. Among these, the adsorption is considered as the best method for the removal and recovery of uranium because of its efficiency, low-cost and easy operation of the adsorption-based technologies [134, 135].

Christos Christoua et al. prepared PVP/chitosan blended nanofibers as adsorbent material for the removal of hexavalent uranium, U[VI] from aqueous solutions. By using batch type experiments, the nanofibers have been characterized prior to and after U[VI] adsorption by SEM and FTIR measurements, and the effect of various parameters 


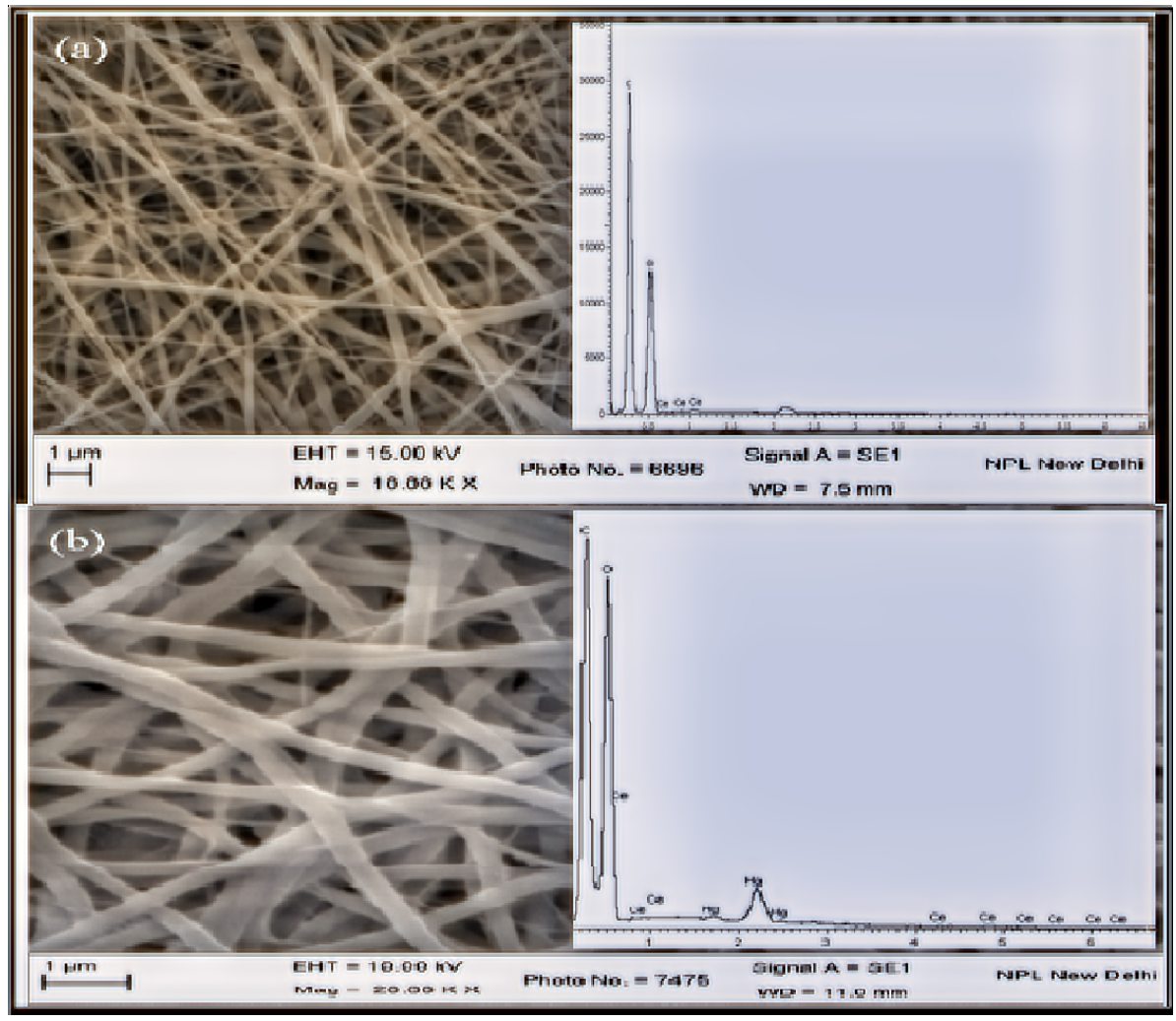

FIG. 10. SEM and EDAX of Ce-PVA-CHT composites nanofibers (a) Before adsorption, (b) After adsorption of $\mathrm{Hg}(\mathrm{II})$ [129]
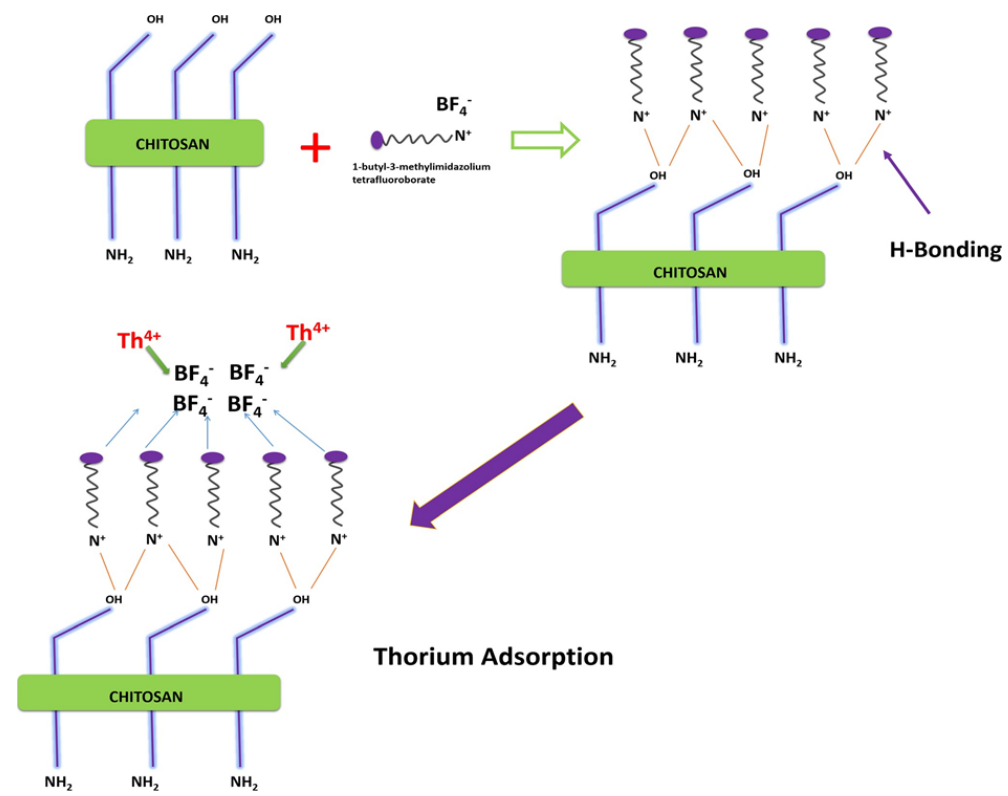

FIG. 11. Interaction between chitosan and RTIL [131] 
such as metal-ion concentration, temperature and contact time on the adsorption efficiency were also investigated. The increased sorption capacity of this nanofiber can be explained by the presence of polar carbonyl group on the fiber, formation of the inner sphere complex between uranium and the fiber. The thermodynamic and kinetic studies revealed a relatively fast kinetics with a rate constant of $k_{1}=0.01 \mathrm{~min}^{-1}$ and an entropy-driven process. From the recycling experiments, it was proved that the material can be reused used up to four cycles with $10 \%$ efficiency loss [136].

Ali Reza Keshtkar et al. prepared Polyvinyl alcohol/tetraethyl orthosilicate/aminopropyltriethoxysilane (PVA/TEOS/APTES) nanofiber membrane by electrospinning method for the adsorption of uranium from aqueous solutions. From SEM, TEM and FTIR and BET analysis the surface area of electro-spun membranes obtained was $153 \mathrm{~m}^{2} / \mathrm{g}$. Experiments were carried out to find out the influence of different sorption parameters like $\mathrm{pH}$, contact time, initial concentration and temperature. The maximum adsorption of uranium ions takes place at a $\mathrm{pH} 4.5$ and at a high temperature of $45^{\circ} \mathrm{C}$. Langmuir, Freundlich and Dubinin - Radushkevich isotherm models were used to describe the equilibrium data of uranium to the prepared membrane at different temperatures $\left(25-45^{\circ} \mathrm{C}\right)$ and the kinetic data were analyzed by pseudo-first-order. The maximum adsorption capacity of uranium ions onto the PVA/TEOS/ APTES hybrid nanofiber membrane was found to be $168.1 \mathrm{mg} / \mathrm{g}$. Thermodynamic parameters showed that the adsorption of uranium onto the electro-spun membrane was feasible, spontaneous and endothermic [137].

\subsection{Nickel}

The discharge of waste water into the rivers and surface waters from the industries may lead to the presence of heavy metals, and organic materials in the water sources which may cause various problems in vital organs of humans and animals [138-140]. Therefore, it should be removed before their diffusion into the ground waters [139]. Nickel has numerous applications in the field of medicine, automobiles, electricals and jewelry. Continuous exposure to nickel and heavy dosage can lead to allergy, cardiovascular and kidney diseases, lung fibrosis, lung and nasal cancer [141].

Alireza Karamipour et al. prepared CS nanofibers coated with $\mathrm{Fe}_{3} \mathrm{O}_{4}$ by weighing a defined amount of chitosan and dissolving it in $3 \%$ acetic acid solvent with continuous stirring for 6 hours to obtain the polymeric solution. The electro-spun nanofibers were coated with $\mathrm{Fe}_{3} \mathrm{O}_{4}$ by immersing in NPs suspensions at room temperature to about 6 $24 \mathrm{hrs}$. The results had shown that the maximum adsorption capacity of $\mathrm{Ni}[\mathrm{II}]$ using $\mathrm{Fe}_{3} \mathrm{O}_{4}$-coated was $163.3 \mathrm{mg} / \mathrm{g}$ at $\mathrm{pH} 5$, an adsorbent dosage of $0.4 \mathrm{~g} / \mathrm{L}$, at a contact time of $5 \mathrm{~h}$, and $25^{\circ} \mathrm{C}$. Kinetic studies had proved that the reaction follows a pseudo second order kinetics and Redlich - Peterson isotherm model, respectively. This modified polymer sample can be used for more than 5 cycles of adsorption [142].

Mehran Bozorgi et al. removed Ni(II) from aqueous solution by using PVA/chitosan/ZnO/APTES nanofiber. Initially, $0.2 \mathrm{~g}$ of chitosan powder in acetic acid and $1 \mathrm{~g}$ of PVA in deionized water is mixed together using a magnetic stirrer for 4 hours. The $\mathrm{ZnO}$ nanoparticles synthesized were modified with APTES. PVA-chitosan composite solution is sonicated with modified $\mathrm{ZnO}$ nanoparticles and was electro-spun to obtain the desired nanofiber. The properties of nanofibers vary with $\mathrm{ZnO}-\mathrm{NH}_{2}$ loading. The TGA analysis showed that $\mathrm{PVA} / \mathrm{Chitosan} / \mathrm{ZnO}-\mathrm{NH}_{2}$ has higher thermal stability in comparison with PVA/Chitosan adsorbent. From the SEM analysis, it was found that the average diameter

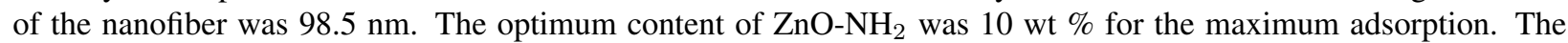
maximum adsorption for $\mathrm{Ni}^{2+}$ by the nanofiber is $0.851 \mathrm{mmol} / \mathrm{g}$ at $45^{\circ} \mathrm{C}$, which is double the value of the cast. The equilibrium data is well fitted with the Langmuir model. It follows a double exponential kinetic model [143].

Umma Habiba et al. synthesized chitosan/polyvinyl alcohol [PVA]/zeolite nanofibrous composite membrane via electrospinning. The characterization of the resulting nanofiber was done by electron microscopy, X-Ray diffraction, Fourier transform infrared spectroscopy, swelling test, and adsorption test. The nanofiber obtained was bead free. The resulting membrane was stable in distilled water, acidic, and basic media. Kinetic study showed that adsorption rate was high. Adsorption of $\mathrm{Ni}$ (II) on nanofibrous membrane follows pseudo second order kinetics and can be best explained by Langmuir adsorption isotherm. The adsorption rate decreases at high concentrations. The adsorption capacity of nanofiber was still retained after five recycling runs; this indicates the reusability of chitosan/PVA/zeolite nanofibrous membrane [144].

Mahtab Jafarnejad et al. described a multi-functionalized polyether sulfone [PES]/chitosan [CS] $/ \mathrm{Fe}_{3} \mathrm{O}_{4}-\mathrm{NH}_{2}-\mathrm{SH}$ nanofiber was prepared and applied for single and simultaneous removal of $\mathrm{Ni}[\mathrm{II}]$ ions from the water systems. $\mathrm{Fe}_{3} \mathrm{O}_{4}$ nanoparticles were synthesized by co-precipitation method and were loaded with $\mathrm{Fe}_{3} \mathrm{O}_{4}-\mathrm{NH}_{2}-\mathrm{SH}$ content. The authors have studied the simultaneous effects of solution $\mathrm{pH}$, adsorbent dosage and $\mathrm{Fe}_{3} \mathrm{O}_{4}-\mathrm{NH}_{2}-\mathrm{SH}$. The composite nanofiber $\mathrm{PES} / \mathrm{CS} / \mathrm{Fe}_{3} \mathrm{O}_{4}-\mathrm{NH}_{2}-\mathrm{SH}$ was prepared via electrospinning technique. The adsorption of nickel ion optimized with the parameters, $\mathrm{pH}$, adsorbent dosage, $\mathrm{Fe}_{3} \mathrm{O}_{4}-\mathrm{NH}_{2}-\mathrm{SH}$ load, the contact time and temperature. Kinetic data suited to the double-exponential model and a monolayer adsorption indicates the Langmuir adsorption model. The maximum adsorption capacity of $\mathrm{CS} / \mathrm{PES} / \mathrm{Fe}_{3} \mathrm{O}_{4}-\mathrm{NH}_{2}-\mathrm{SH}$ was $95.3 \mathrm{mg} / \mathrm{g}$. The main advantage of this nanofiber was their adsorption capacity was retained for 4 desorption steps. In a binary system of ions, the adsorption capacity decreased with the increase of competitive ion concentration [145]. 


\subsection{Arsenic}

Arsenic is a commonly distributed element in the natural environment, particularly in the ground water. Water contaminated with arsenic may lead to many health problems such as bladder cancer, skin lesions etc. As many technologies have been developed to remove arsenic from water, adsorption is the best method among them.

L-L. Min et al. synthesized chitosan based membrane [CS-ENM] by electrospinning process using acetic acid as solvent for the removal of arsenate from water. The resulting chitosan based fibrous membrane was highly porous, with a large specific surface area. Due to these factors, the adsorption capacity was higher than the most reported chitosan adsorbents and the value is about $30.8 \mathrm{mg} / \mathrm{g}$. It was also noted that the $\mathrm{pH}$ value has shown a marked influence on the adsorption of As[V]. The result shows that the adsorption will be maximum at a lower $\mathrm{pH}$ [146].

Ping Tan et al. showed that the effective removal of arsenate from water at neutral $\mathrm{pH}$ can be done by using immobilizing chitosan nanofiber with lanthanum. An homogeneous solution of $4 \% \mathrm{w} / \mathrm{v}$ chitosan and $4 \% \mathrm{w} / \mathrm{v}$ PEO are prepared in acetic acid solvent and is loaded with lanthanum. The solution is electro-spun to obtain CS/PEO nanofiber doped with La. Lanthanum loading has marked influence on the adsorption of arsenate ion. The adsorption of arsenate ion using this lanthanum-doped chitosan nanofiber was about $83.6 \mathrm{mg} / \mathrm{g}$, which is more than that of any other chitosan based nanofiber. This method was effective at wide range of $\mathrm{pH}$ values. The effect of doping of metal oxide $\mathrm{Fe}, \mathrm{Zr}, \mathrm{Cu}, \mathrm{Fe} / \mathrm{Zr}$, and $\mathrm{Fe} / \mathrm{Cu}$ with the nanofiber was also evaluated. The use of $\mathrm{Fe}$-oxide impregnated mat give maximum adsorption of arsenate compared to other oxides. This could be explained on the basis of the formation of inner sphere complexes with Fe oxide [147].

L-L. Min et al. reported that a novel iron doped chitosan electro-spun nanofiber can be used for the effective removal arsenate from water at neutral $\mathrm{pH}$, proving a vital role in the removal of arsenate. Fig. 12 indicates the formation of $\mathrm{Fe}$ doped chitosan nanofibres. Many works reported arsenate removal at acidic and basic conditions. This work proved that Fe doped chitosan fibers will remove arsenate ions from water over a wide range of $\mathrm{pH}$ values, even at neutral $\mathrm{pH}$. The maximum adsorption capacity was noticed at $36.1 \mathrm{mg} / \mathrm{g}$. When the adsorbent dosage increased above $0.3 \mathrm{~g} / \mathrm{L}$, more than $90 \%$ removal efficiency was shown by the fiber. The XPS analysis suggested that the amino groups on chitosan backbone results in the adsorption of As[III] from the water samples [148].

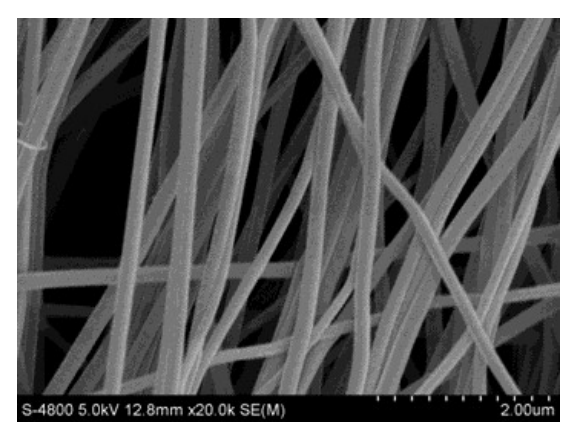

(a)

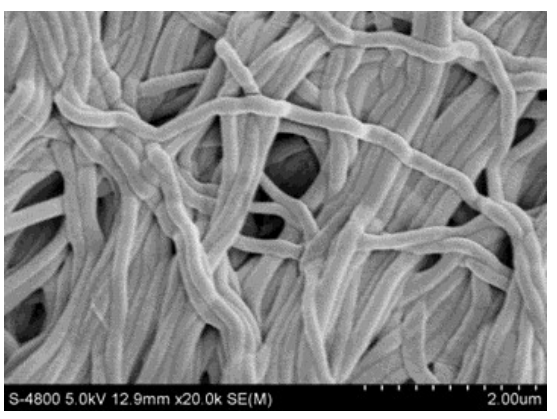

(c)

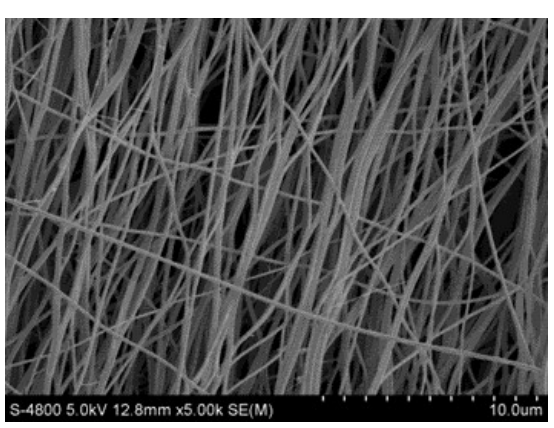

(b)

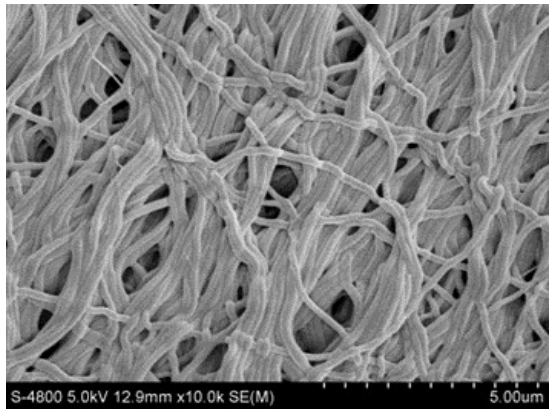

(d)

FIG. 12. SEM images of Fe doped chitosan fibers [148]

Reena Sharma et al. synthesized a Ce-CHT/PVA composite nanofiber through an electrospinning technique by mixing $4 \mathrm{wt} \%$ of CHT in $2 \% \mathrm{v} / \mathrm{v}$ of formic acid and PVA in $2 \%$ acetic acid in the ratio of 7:3 under constant stirring for about $4-5 \mathrm{hrs}$. The solution was electro-spun to obtain the desired nanofiber. Ce-CHT/PVA composite nanofiber showed greater efficiency in the removal of As[III] than CHT/PVA. A high adsorption of As[III] compared to the 
other adsorbents was due to the high surface area and presence of more active sites. The kinetic studies revealed that in the first 10 minutes, over $80 \%$ of As[III] was removed and the adsorption capacity was about $18 \mathrm{mg} / \mathrm{g}$, which was confirmed from the Langmuir adsorption isotherm [149].

The work of Ling-Li-Min, et al. reported the removal of As[V] using that Iron functionalized chitosan/PEO electro-spun nanofiber [ICS-PEO-ENF]. This can be synthesized by electrospinning a mixture of chitosan, PEO, and $\mathrm{Fe}^{3+}$ followed by crosslinking with the ammonia vapor. The experimental results has shown that the As[V] adsorption was decreased with the increased ionic strength, and this was due to the outer sphere complexion of As[V] on the nanofiber. Variation of $\mathrm{pH}$ also influences the adsorption. The adsorption isotherm was well described by Freundlich model and the maximum adsorption capacity was found to be up to $11.2 \mathrm{mg} / \mathrm{g}$ at $\mathrm{pH} 7.2$ [150].

\section{Conclusion}

Chitosan is a remarkable green polymer with numerous applications in a variety of fields due to its biocompatibility and biodegradability, and also a renewable resource that can be found in abundance in nature. Nanofibers have a large surface area, which confers additional properties, giving them an advantage over conventional fibers. Bringing the two ideas together, chitosan and nanofibers could result in amazing materials of research interest. This is not, however, an easy mission. Natural polymers seem to be difficult substrates for electrospinning techniques due to their high molecular weights. Several methods were used to solve this challenge. The selection of a suitable solvent facilitates nanofiber fabrication. The use of chitosan blends with other synthetic or natural polymers, as well as chemical modifications, was another technique for creating smooth nanofibers. Chitosan based electro-spun nanofibers have proven capacity in the removal of heavy metals from water due to their properties like high adsorption capacity, nontoxicity, hydrophilicity, fast kinetics, and reusability. The disadvantages of these polymers include their low stability and poor mechanical characteristics. The mechanical properties, especially the porosity of chitosan-based electrospun nanofibers, are influenced by the production methods and their blending and modifications, which enhances the removal efficiency. This review provides a comparison of adsorption of different heavy metals by electro-spun nanofibers of different chitosan blends. From the literature, it was understood that, temperature, $\mathrm{pH}$, contact time, concentration were the process parameters which exert influences upon the fibers' adsorption capacities. Electrospinning parameters like voltage distance between tip and collector, flow rate also affects the properties of fiber. Blending with other polymers and doping with nanometals and metal oxides are the two significant factors that enhance metal removal by the chitosan fibers. The blending ratio, nature of dopant, and doping load have a favorable impact on the fiber characteristics. It was evident from the works; the metal adsorption by nanofibers follows pseudo second order kinetics in most cases. Currently the world is dealing with a serious problem of heavy metal contamination in water, which is detrimental to the entire ecosystem. Water purification systems can be better understood and developed in the future by simulating purification processes. This article may spur the development of more chitosan-based nanofibers for heavy metal removal as well as to contribute to water treatment industry. In addition to the nanofibers discussed here, many electro-spun chitosan nanofibers and its composites can be employed for the effective removal of metals which is shown in Table 1.

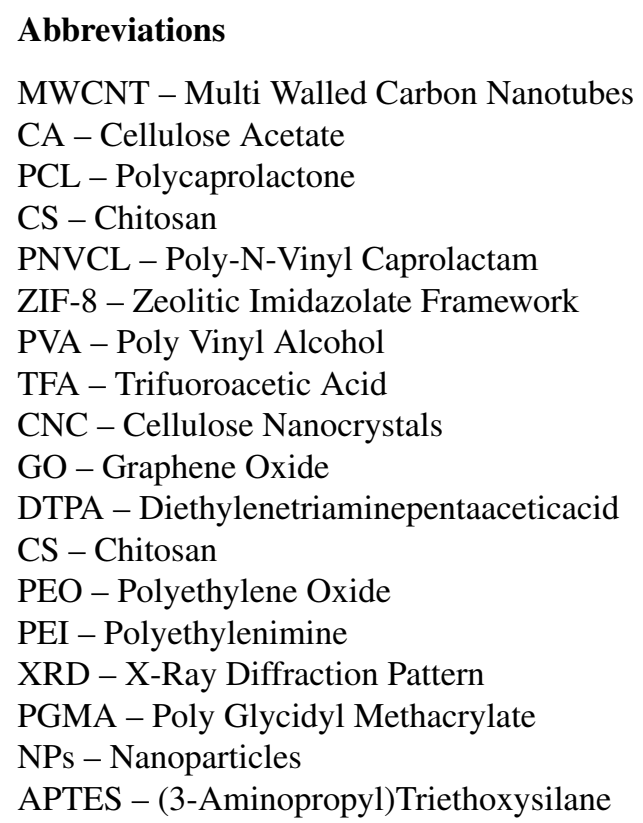


TABLE 1. Comparative adsorption of different metal ions by chitosan blends

\begin{tabular}{|c|c|c|c|c|}
\hline Nanofiber & Metal ion & $\begin{array}{c}\text { Maximum } \\
\text { adsorption } \\
\mathrm{mg} / \mathrm{g}\end{array}$ & Adsorption Model & Ref \\
\hline Chitosan - Graphene oxide & $\mathrm{Cu}[\mathrm{II}]$ & 423.8 & Redlich - Peterson isotherm model & {$[102]$} \\
\hline Chitosan - Graphene oxide & $\mathrm{Cr}[\mathrm{VI}]$ & 310.4 & Redlich - Peterson isotherm model & [102] \\
\hline Chitosan-Polyethylene oxide & $\mathrm{Cu}[\mathrm{II}]$ & 120.6 & Dubinin - Daskovich model & [107] \\
\hline Chitosan-Polyethylene oxide & $\mathrm{Ni}[\mathrm{II}]$ & 35.24 & Dubinin - Daskovich model & [107] \\
\hline $\begin{array}{l}\text { Chitosan-diethylene triamine } \\
\text { pentaacetate- polyethylene oxide }\end{array}$ & $\mathrm{Pb}[\mathrm{II}]$ & 144.7 & Dubinin - Daskovich model & [107] \\
\hline $\begin{array}{l}\text { Chitosan-diethylene triamine } \\
\text { pentaacetate- polyethylene oxide }\end{array}$ & $\mathrm{Ni}[\mathrm{II}]$ & 46.95 & Dubinin - Daskovich model & [107] \\
\hline $\mathrm{TiO}_{2}$ coated chitosan & $\mathrm{Pb}[\mathrm{II}]$ & 475.5 & Redlich - Peterson isotherm model & [110] \\
\hline $\mathrm{TiO}_{2}$ entrapped chitosan & $\mathrm{Pb}[\mathrm{II}]$ & 579.1 & Redlich - Peterson isotherm model & [110] \\
\hline $\begin{array}{l}\text { chitosan/sulfydryl-functionalized } \\
\text { graphene oxide composite }\end{array}$ & $\mathrm{Pb}[\mathrm{II}]$ & 447 & Freundlich & {$[153]$} \\
\hline Polyaniline grafted Chitosan & $\mathrm{Pb}[\mathrm{II}]$ & 13.23 & Freundlich & [154] \\
\hline Chitosan/Epichlorohydrin & $\mathrm{Pb}[\mathrm{II}]$ & 34.13 & & {$[155]$} \\
\hline $\begin{array}{l}\text { Chitosan/cellulose [CS/CL] } \\
\text { nanofibers }\end{array}$ & $\mathrm{Pb}[\mathrm{II}]$ & 112.6 & & [156] \\
\hline $\begin{array}{l}\text { chitosan/ } \mathrm{TiO}_{2} \text { composite Nano fibrous } \\
\text { adsorbents }\end{array}$ & $\mathrm{Cu}[\mathrm{II}]$ & 579.1 & & [98] \\
\hline Chitosan Stacking Membranes & $\mathrm{Cu}[\mathrm{II}]$ & 276.2 & Multilayer adsorption & {$[157]$} \\
\hline Chitosan electro spun on polyester & $\mathrm{Cr}[\mathrm{VI}]$ & 16.5 & Adams Bohart Model & [151] \\
\hline chitosan [CA-PCL/CS] nanofibers & $\mathrm{Cr}[\mathrm{VI}]$ & 126 & Freundlich & [79] \\
\hline $\begin{array}{l}\text { Chitosan/cellulose [CS/CL] } \\
\text { nanofibers }\end{array}$ & $\mathrm{As}[\mathrm{V}]$ & 39.4 & & [156] \\
\hline Chitosan/Alumina & $\mathrm{As}[\mathrm{V}]$ & 96.46 & & [158] \\
\hline $\begin{array}{l}\text { Chitosan based electro spun nano fiber } \\
\text { membrane }\end{array}$ & $\mathrm{As}[\mathrm{V}]$ & 30.8 & Langmuir & [146] \\
\hline $\begin{array}{l}\text { electro spun DTPA-modified chi- } \\
\text { tosan/polyethylene oxide nanofibers }\end{array}$ & $\mathrm{Ni}[\mathrm{II}]$ & 56 & $\begin{array}{l}\text { Freundlich, Langmuir, Temkin and } \\
\text { Dubinin - Radushkevich isotherm } \\
\text { models }\end{array}$ & {$[107]$} \\
\hline \multirow[t]{5}{*}{ Magnetic Chitosan } & $\mathrm{Ni}[\mathrm{II}]$ & 22.07 & & \multirow[t]{4}{*}[159]{} \\
\hline & $\mathrm{Pb}[\mathrm{II}]$ & 27.95 & & \\
\hline & $\mathrm{Hg}[\mathrm{II}]$ & 23.03 & & \\
\hline & $\mathrm{Cd}[\mathrm{II}]$ & 27.83 & & \\
\hline & $\mathrm{Cu}[\mathrm{II}]$ & 216.6 & & {$[160]$} \\
\hline Chitosan/Diethylenetriamine & $\mathrm{U}[\mathrm{VI}]$ & 177.9 & & [161] \\
\hline $\begin{array}{l}\text { Chitosan/ polyethylene oxide/ carbon- } \\
\text { ated nanofibers }\end{array}$ & $\mathrm{Cu}[\mathrm{II}]$ & 195.3 & & [162] \\
\hline Chitosan PVC & $\mathrm{Cu}[\mathrm{II}]$ & 161.3 & & {$[163]$} \\
\hline
\end{tabular}


PAA - Peraceticacid

PLLA - Poly L-Lactic Acid

PNC - Phosphorylated Nano Cellulose

MOF - Metal Oxide Frame Works

nCHS - Nano Chitosan

CHT - Chitosan

RTIL - Room Temperature Ionic Liquid

BMIM-BF4 - 1-Butyl-3-Methylimidazolium Tetrafluoroborate

PES - Poly Ether Sulfone

$\mathrm{SH}$ - Thiol

ICS-ENF - Iron Functionalized Chitosan Electro Spun Nano Fiber

CL - Cellulose

\section{References}

[1] Allan G.G., Altman L.C., et al. Biomedical applications of chitin and chitosan. In: Chitin, chitosan and related enzymes. Zikakis J.P. ed., Academic Press, Inc., 1984, P. 119-133.

[2] Dutta P.K., Dutta J., Tripathi V.S. Chitin and chitosan: Chemistry, properties and applications. J. of Scientific and Industrial Research, 2004, 60, P. 20-31.

[3] Muzzarelli R.A.A. Chitin Enzymology. Alda Tecnografica, Ancona, Italy, 1993.

[4] Muzzarelli, R. In vivo biochemical significance of chitin-based medical items. In: Dumitriu, S. Ed., Polymeric Biomaterials. Marcel Dekker, Inc, New York, 1994, P. 179-197.

[5] Muzzarelli R.A.A. Chitin enzymology. Atec Edizioni, Ancona, Italy, 1996.

[6] Muzzarelli R.A.A. Chitin. The Polymeric Materials Encyclopedia. Ed. Salamone J.C. CRC Press, Inc., BocaRaton, USA, 1996.

[7] Muzzarelli R.A.A. Natural chelating polymers. Pergamon Press, New York, 1973, 83 p.

[8] Zikakis J.P. Chitin, chitosan and related enzymes. Academic Press, Orlando, 1984.

[9] Kurita K. Chemistry and application of chitin and chitosan. Polymer Degradation and Stability, 1998, 59 (2), P. $117-120$.

[10] Evans J.R., Davids W.G., MacRae J.D., Amirbahman A. Kinetics of cadmium uptake by chitosan-based crab shells. Water Research, 2002, 36, P. 3219-3226.

[11] Lu G., Yao X., Wu X., Zhan T. Determination of the total iron by chitosan-modified glassy carbon electrode. Microchemical Journal, 2001, 69, P. 81-87.

[12] Wu F., Tseng R., Juang R. Comparative adsorption of metal and dye on flake- and bead-types of chitosans prepared from fishery wastes. $J$. of Hazardous Materials B, 2000, 73, P. 63-75.

[13] Guibal E., Dambies L., Milot C., Roussy, J. Influence of polymer structural parameters and experimental conditions on metal anion sorption by chitosan. Polymer International, 1999, 48, P. 671-680.

[14] Yang Z., Zhuang L., Tan, G. Preparation and adsorption behavior for metal of chitosan crosslinked by dihydroxy azacrown ether. J. of Applied Polymer Science, 2002, 85, P. 530-535.

[15] Onsoyen E., Skaugrud O. Metal recovery using chitosan. J. of Chemical Technolnology and Biotechnology, 1990, 49, P. $395-404$.

[16] Yang Z., Yuan Y. Studies on the synthesis and properties of hydroxyl azacrown ether-grafted chitosan. J. of Applied Polymer Science, 2001, 82, P. 1838-1843.

[17] Goissis G., Junior E.M., et al. Biocompatibility studies of anionic collagen membranes with different degree of glutaraldehyde cross-linking. Biomaterials, 1999, 20, P. 27-34

[18] Guibal E., Milot C., Tobin J.M. Metal-anion sorption by chitosan beads: Equilibrium and kinetic studies. Industrial and Engineering Chemistry Research, 1998, 37, P. 1454-1463.

[19] Hsien T.-Y., Rorrer G.L. Heterogenous cross linking of chistosan beads: Kinetics, modeling and influence on cadmium ion adsorption capacity. Industrial and Engineering Chemistry Research, 1997, 36, P. 3631-3638.

[20] Huang R.Y.M., Pal R., Moon G.Y. Crosslinked chitosan composite membrane for the pervaporation dehydration of alcohol mixtures and enhancement of structural stability of chitosan/polysulfone composite membranes. J. of Membrane Science, $1999,160,17$.

[21] Wei Y.C., Hudson S.M., Mayer J.M., Kaplan D.L. Crosslinking of chitosan fibers. J. of Polymer Science Part A: Polymer Chemistry, 1992, 30, P. 2187-2193.

[22] Schmidt C.E., Baier J.M. Cellular vascular tissues: Natural biomaterials for tissue repair and tissue engineering. Biomaterials, 2000, 21, P. 2215-2231.

[23] Dietzel J.M., Kleinmeyer J.D., Hirvonen J.K., Tan N.C.B. Controlled deposition of electrospun poly (ethylene oxide) fibers. Polymer, 2001, 42 (19), P. 8163-8170.

[24] Teo W.E., Ramakrishna S. A review on electrospinning design and nanofibre assemblies. Nanotechnology, 2006,17 (14), R89-R106.

[25] Geng X., Kwon O.H, Jang J. Electrospinning of chitosan dissolved in concentrated acetic acid solution. Biomaterials, 2005, 26 (27), P. 54275432.

[26] Shin Y.M., Hohman M.M, Brenner M.P., Rutledge G.C. Experimental characterization of electrospinning: The electrically forced jet and instabilities. Polymer, 2001, 42, P. 9955-9967.

[27] Jaeger R., Schönherr H., Vancso G. Chain packing in electro-spun poly [ethylene oxide] visualized by atomic force microscopy. Macromolecules, 1996, 29 (23), P. 7634-7636.

[28] Taylor G. Disintegration of water drops in an electric field. Proceedings of the Royal Society of London A, 1964,280 (1382), P. $383-397$.

[29] Lai X., Wu D., Sun D. Electro spinning under sub critical voltage. 5th IEEE international conference on nano/micro engineered and molecular systems (NEMS), 2010, P. 1170-1173. 
[30] Electrospinning set up. Mechanics Electronics Computer Corporation. URL: http://www.bioeng.nus.edu.sg/nanobio/ESmachines/MECC.pdf. Accessed on 8th September 2014.

[31] Multi jet spinneret. Mechanics Electronics Computer Corporation. URL: http://www.mecc.co.jp/en/html/nanon/spinneret/multijet.html. Accessed on 8th September 2014.

[32] Horzum N., Boyaci E., et al. Sorption efficiency of chitosan nanofibers toward metal ions at low concentrations. Biomacromolecules, 2010, 11 (12), P. 3301-3308.

[33] Mahmoud M.E., Osman M.M., Hafez O.F., Elmelegy E. Removal and preconcentration of lead (II), copper (II), chromium (III) and iron (III) from wastewaters by surface developed alumina adsorbents with immobilized 1-nitroso-2-naphthol. J. of Hazardous Materials, 2010, 173, P. 349-357.

[34] Shukla S.R., Pai R.S., Shendarkar A.D. Adsorption of Ni(II), Zn(II) and Fe(II) on modified coir fibres. Separation and Purification Technology, 2006, 47, P. 141-147.

[35] Jain C.K., Singhal D.C., Sharma M.K. Adsorption of zinc on bed sediment of River Hindon: adsorption models and kinetics. J. of Hazardous Materials, 2004, 114, P. 231-239.

[36] Sekar M., Sakthi V., Rengaraj S. Kinetics and equilibrium adsorption study of lead[II] onto activated carbon prepared from coconut shell. $J$. of Colloid and Interface Science, 2004, 79, P. 307-313.

[37] Iqbal M., Saeed A., Zafar S.I. Hybrid biosorbent: An innovative matrix to enhance the biosorption of Cd[II] from aqueous solution. J. of Hazardous Materials, 2007, 148, P. 47-55.

[38] Navarro R.R., Wada S., Tatsumi K. Heavy metal precipitation by polycation-polyanion complex of PEI and its phosphonomethylated derivative. J. of Hazardous Materials, 2005, 123, P. 203-209.

[39] Panayotova T., Dimova-Todorova M., Dobrevsky I. Equilibrium and kinetic modelling of iron adsorption by eggshells in a batch system: Effect of temperature. Desalination, 2007, 206, P. 135-140.

[40] Dabrowski A., Hubicki Z., Podkoscielny P., Robens E. Selective removal of the heavy metal ions from waters and industrial wastewaters by ion-exchange method. Chemosphere, 2004, 56, P. 91-106.

[41] Mbareck C., Nguyen Q.T., Alaoui O.T., Barillier D. Elaboration, characterization and application of polysulfone and polyacrylic acid blends as ultrafiltration membranes for removal of some heavy metals from water. J. of Hazardous Materials, 2009, 171, P. 93-101.

[42] O'Connell D.W., Birkinshaw C., O'Dwyer T.F. Heavy metal adsorbents prepared from the modification of cellulose: A review. Bioresource Technology, 2008, 99, P. 6709-6724.

[43] Zhu S., Yang N., Zhang D. Poly(N,N-dimethylaminoethyl methacrylate) modification of activated carbon for copper ions removal. Material Chemistry and Physics, 2009, 113, P. 784-789.

[44] Zhang S., Li X., Chen J.P. Preparation and evaluation of a magnetite-doped activated carbon fiber for enhanced arsenic removal. Carbon, 2010, 48, P. 60-67.

[45] Mishra P.C., Patel R.K. Removal of lead and zinc ions from water by low cost adsorbents. J. of Hazardous Materials, 2009, 168 (1), P. 319 325.

[46] Dragan E.S., Dinu M.V., Timpu D. Preparation and characterization of novel composites based on chitosan and clinoptilolite with enhanced adsorption properties for $\mathrm{Cu}^{2+}$. Bioresource Technology, 2010, 101, P. 812-817.

[47] Wang X., Zheng Y., Wang A. Fast removal of copper ions from aqueous solution by chitosan-g-poly(acrylic acid)/attapulgite composites. $J$. of Hazardous Materials, 2009, 168, P. 970-977.

[48] Shen W., Chen S., et al. Adsorption of $\mathrm{Cu}(\mathrm{II})$ and $\mathrm{Pb}(\mathrm{II})$ onto diethylenetriamine-bacterial cellulose. Carbohydrate Polymers, 2009, 75, P. 110-114.

[49] Jiang Y., Pang H., Liao B. Removal of copper(II) ions from aqueous solution by modified bagasse. J. of Hazardous Materials, 2009, 164, P. 1-9.

[50] Zhang G., Qu R., et al. Adsorption for metal ions of chitosan coated cotton fiber. J. of Applied Polymer Science, 2008,110, P. $2321-2327$.

[51] Sun S., Wang A. Adsorption properties of N-succinyl-chitosan and cross-linked N-succinyl-chitosan resin with Pb(II) as template ions. Separation and Purification Technology, 2006, 51, P. 409-415.

[52] Kavakli P.A., Güven O. Removal of concentrated heavy metal ions from aqueous solutions using polymers with enriched amidoxime groups. J. of Applied Polymer Science, 2004, 93, P. 1705-1710.

[53] Bilba N., Bilba D., Moroi G. Synthesis of a polyacrylamidoxime chelating fiber and its efficiency in the retention of palladium ions. J. of Applied Polymer Science, 2004, 92, P. 3730-3735.

[54] Gong B. Synthesis of polyacrylaminoimidazole chelating fiber and properties of concentration and separation of trace Au, $\mathrm{Hg}$ and $\mathrm{Pd}$ from samples. Talanta, 2002, 57, P. 89-95.

[55] Chang X., Su Q., et al. Efficiency and application of poly(acryldinitrophenylamidrazone-dinitroacrylphenylhydrazine) chelating fiber for preconcentrating and separating trace $\mathrm{Au}(\mathrm{III}), \mathrm{Ru}(\mathrm{III}), \mathrm{In}(\mathrm{III}), \mathrm{Bi}(\mathrm{III}), \mathrm{Zr}(\mathrm{IV}), \mathrm{V}(\mathrm{V}), \mathrm{Ga}(\mathrm{III})$ and Ti(IV) from solution samples. Talanta, 2002, 57, P. 253-261.

[56] Deng S., Bai R. Removal of trivalent and hexavalent chromium with aminated polyacrylonitrile fibers: performance and mechanisms. Water Research, 2004, 38, P. 2424-2432.

[57] Deng S., Bai R., Chen J.P. Aminated polyacrylonitrile fibers for lead and copper removal. Langmuir, 2003, 19, P. 5058-5064.

[58] Ma N., Yang Y., Chen S., Zhang Q. Preparation of amine group-containing chelating fiber for thorough removal of mercury ions. J. of Hazardous Materials, 2009, 171, P. 288-293.

[59] Ko Y.G., Choi U.S., Park Y.S., Woo J.W. Fourier transform infrared spectroscopy study of the effect of pH on anion and cation adsorption onto poly(acrylo-amidino diethylenediamine). J. of Polymer Science Part A: Polymer Chemistry, 2004, 42, P. $2010-2018$.

[60] Huang Y., Miao Y-E., Liu T. Electrospun fibrous membranes for efficient heavy metal removal. J. of Applied Polymer Science, 2014, 131 (19), 40864.

[61] Zhang L., Zeng Y.X., Cheng Z.J. Removal of heavy metal ions using chitosan and modified chitosan: A review. J. of Molecular Liquids, 2016, 214, P. 175-191.

[62] Rui X., Hongyang M.A., Venkateswaran S., Benjamin S. Electrospun nanofibrous adsorption membranes for wastewater treatment: Mechanical strength enhancement. Chemical Research in Chinese Universities, 2021, 37 (3), P. 355-365. 
[63] Gandavadi D., Sundarrajan S., Ramakrishna S. Bio-Based Nanofibers involved in wastewater treatment. Macromolecular Materials and Engineering, 2019, 304, 1900345.

[64] Dehghani M.H., Sanaei D., Ali I., Bhatnagar A. Removal of chromium(VI) from aqueous solution using treated waste newspaper as a low-cost adsorbent: Kinetic modeling and isotherm studies. J. of Molecular Liquids, 2016, 215, 671.

[65] Yang J., Yu M., Chen W. Adsorption of hexavalent chromium from aqueous solution by activated carbon prepared from longan seed: Kinetics, equilibrium and thermodynamics. J. of Industrial and Engineering Chemistry, 2015, 21, 414.

[66] Chen L., Chen Z., Chen D., Xiong W. Removal of hexavalent chromium from contaminated waters by ultrasound-assisted aqueous solution ball milling. J. of Environmental Sciences, 2017, 52, 27.

[67] Yuan P., Liu D., et al. Removal of hexavalent chromium [Cr[VI]] from aqueous solutions by the diatomite supported/unsupported magnetite nanoparticles. J. of Hazardous Materials, 2010, 173, P. 614-621.

[68] Sun L., Zhang L., et al. Chitosan modified FeO nanowires in porous anodic alumina and their application for the removal of hexavalent chromium from water. J. of Material Chemistry, 2011, 21, P. 5877-5880.

[69] Hu J., Chen C., Zhu X., Wang X. Removal of chromium from aqueous solution by using oxidized multiwalled carbon nanotubes. J. of Hazardous Materials, 2009, 162, P. 1542-1550.

[70] Amalraj A., Selvi M.K., et al. Efficient removal of toxic hexavalent chromium from aqueous solution using threonine doped polypyrrole nanocomposite. J. of Water Process Engineering, 2016, 13, 88.

[71] Harijan D.K.L, Chandra V. Polyaniline functionalized graphene sheets for treatment of toxic hexavalent chromium. J. of Environmental Chemical Engineering, 2016, 4, 3006.

[72] Bhaumik M., Setshedi K., Maity A., Onyango M.S. Chromium(VI) removal from water using fixed bed column of polypyrrole/Fe $\mathrm{O}_{4}$ nanocomposite. Separation and Purification Technology, 2013, 110, 11.

[73] Won S.W., Kotte P., et al. Biosorbents for recovery of precious metals. Bioresource Technology, 2014, $160,203$.

[74] Zhou J., Wang Y., et al. Effective removal of hexavalent chromium from aqueous solutions by adsorption on mesoporous carbon microspheres. J. of Colloid and Interface Science, 2016, 462, 200.

[75] Mishra S., Verma N. Carbon bead-supported hollow carbon nanofibers synthesized via templating method for the removal of hexavalent chromium. J. of Industrial and Engineering Chemistry, 2016, 36, 346.

[76] Gupta V.K., Ali I. Environmental water: Advances in treatment, remediation and recycling. Elsevier, Netherlands, 2012.

[77] Beheshti H., Irani M., et al. Removal of $\mathrm{Cr}[\mathrm{VI}]$ fromaqueous solutions using chitosan/MWCNT/Fe ${ }_{3} \mathrm{O}_{4}$ composite nanofibers-batch and column studies. Chemical Engineering Journal, 2015, 284 (15), P. 557-564.

[78] Kummer G., Schonhart C., et al. Development of nanofibers composed of chitosan/nylon 6 and tannin/nylon 6 for effective adsorption of $\mathrm{Cr}[\mathrm{VI}]$. J. of Polymers and the Environment, 2018, 26, P. 4073-4084

[79] Ma L., Shi X., et al. Electrospun cellulose acetate polycaprolactone/chitosan core-shell nanofibers for the removal of Cr[VI]. Physica Status Solidi (A) Applications and Materials, 2019, 216 (22), 1900379.

[80] Li L., Li Y., Cao L., Yang C. Enhanced chromium [VI] adsorption using nanosized chitosan fibers tailored by electrospinning. Carbohydrate Polymers, 2015, 125, P. 206-213.

[81] Bahmani E., Koushkbaghi S., et al. Fabrication of novel chitosan-g-PNVCL/ZIF-8 composite nanofibers for adsorption of Cr[VI], As[V] and phenol in a single and ternary systems. Carbohydrate Polymers, 2019, 224, 115148.

[82] Yan E., Cao M., et al. A novel adsorbent based on magnetic $\mathrm{Fe}_{3} \mathrm{O}_{4}$ contained polyvinyl alcohol/chitosan composite nanofibers for chromium [VI] removal. Solid State Sciences, 2017, 72, P. 94-102.

[83] Nooney R.I., Kalyanaraman M., Kennedy G., Maginn E.J. Heavy metal remediation using functionalized mesoporous silicas with controlled macrostructure. Langmuir, 2000, 17, P. 528-533.

[84] Nourbakhsh M., Illhan S., Ozdag H. Biosorption of $\mathrm{Cr}^{6+}, \mathrm{Pb}^{2+}$ and $\mathrm{Cu}^{2+}$ ions in industrial waste water on Bacillus sp. Chemical Engineering Journal, 2002, 85, P. 351-355.

[85] Sokol R.Z., Berman N. The effect of age of exposure on lead-induced testicular toxicity. Toxicology, 1991, 69 (3), P. 269-278.

[86] Ahamed M., Siddiqui M.K.J. Environmental lead toxicity and nutritional factors. Clinical Nutrition, 2007,26 (4), P. 400-408.

[87] Jarosińska D., Peddada S., Rogan W.J. Assessment of lead exposure and associated risk factors in urban children in Silesia, Poland. Environmental Research, 2004, 95 (2), P. 133-142.

[88] Gercel O., Gercel H.F. Adsorption of lead[II] ions from aqueous solutions by activated carbon prepared from biomass plant material of Euphorbia rigida. Chemical Engineering Journal, 2007, 132 (1-3) P. 289-297.

[89] Irani M., Amjadi M., Mousavian M.A. Comparative study of lead sorption on to natural perlite, dolomite and diatomite. Chemical Engineering Journal, 2011, 178, P. 317-323.

[90] Shi T., Jia S., et al. Adsorption of $\mathrm{Pb}[\mathrm{II}], \mathrm{Cr}[\mathrm{II}], \mathrm{Cu}[\mathrm{II}], \mathrm{Cd}[\mathrm{II}]$ and $\mathrm{Ni}[\mathrm{II}]$ on to a vanadium mine tailing from aqueous solution. J. of Hazardous Materials, 2009, 169, P. 838-846.

[91] Dastbaz A., Keshtkar A.R. Adsorption of $\mathrm{Th}^{4+}, \mathrm{U}^{6+}, \mathrm{Cd}^{2+}$, and $\mathrm{Ni}^{2+}$ from aqueous solution by a novel modified polyacrylonitrile composite nanofiber adsorbent prepared by electrospinning. Applied Surface Science, 2014, 293, P. 336-44.

[92] Lu Y., Wu Z., et al. Hydrophilic PVA-co PE nanofiber membrane functionalized with iminodiacetic acid by solid-phase synthesis for heavy metal ions removal. Reactive and Functional Polymers, 2014, 82, P. 98-102.

[93] Rad L.R., Momeni A., et al. Removal of Ni2+ and Cd2+ ions from aqueous solutions using electrospun PVA/zeolite nanofibrous adsorbent. Chemical Engineering Journal, 2014, 256, P. 119-127.

[94] Li X., Zhang C., et al. Efficient adsorption of gold ions from aqueous systems with thioamide-group chelating nanofiber membranes. Chemical Engineering Journal, 2013, 229, P. 420-448.

[95] Irani M., Keshtkar A.R., Moosavian M.A. Removal of cadmium from aqueous solution using mesoporous PVA/TEOS/APTES composite nanofiber prepared by solgel/electrospinning. Chemical Engineering Journal, 2012, 200, P. 192-201.

[96] Najafabadi H.H., Irani M., et al. Removal of $\mathrm{Cu}^{2+}, \mathrm{Pb}^{2+}$ and $\mathrm{Cr}^{6+}$ from aqueous solutions using chitosan/grapheme oxide composite nanofibrous adsorbent. RSC Advances, 2015, 5, P. 16532-16539.

[97] Wu S., Li F., et al. Effects of poly[vinylalcohol] [PVA] content on preparation of novel thiol-functionalized mesoporous $\mathrm{PVA}_{\mathrm{S}} \mathrm{SiO}_{2}$ composite nanofiber membranes and their application for adsorption of heavy metal ions from aqueous solution. Polymer, 2010, 51, P. 6203-6211. 
[98] Razzaz A., Ghorban S., et al. Chitosan nanofibers functionalized by $\mathrm{TiO}_{2}$ nanoparticles for the removal of heavy metal ions. J. of the Taiwan Institute of Chemical Engineers, 2016, 58, P. 333-343.

[99] Richard M., Nthumbi J., et al. Method development for flow adsorption and removal of lead and copper in contaminated water using electrospun nanofibers of chitosan blend. Analytical Letters, 2011, 44 (11), P. 1937-1955.

[100] Li Y., Qiu T., Xu X. Preparation of lead-ion imprinted crosslinked electro-spun chitosan nanofiber mats and application in lead ions removal from aqueous solutions. European Polymer Journal, 2013, 49 (6), P. 1487-1494.

[101] Wang D., Cheng W., et al. Electrospun cellulose nanocrystals/chitosan/polyvinyl alcohol nanofibrous films and their exploration to metal ions adsorption. Polymers, 2018, 10, 1046.

[102] Hossein Hadi Najafabadi, Mohammad Irani, et al. Removal of $\mathrm{Cu}^{2+}, \mathrm{Pb}^{2+}$ and $\mathrm{Cr}^{6+}$ from aqueous solutions using a chitosan/graphene oxide composite nanofibrous adsorbent. RSC Adv., 2015, 5, 16532.

[103] Karri V., Schuhmacher M., Kumar V. Heavy metals [Pb, Cd, As and Me Hg] as risk factors for cognitive dysfunction: A general review of metal mixture mechanism in brain. Environmental Toxicology and Pharmacology, 2016, 48, P. 203-213.

[104] Chen L., Zhou S., et al. Heavy metals in food crops, soil, and water in the Lihe River Watershed of the Taihu Region and their potential health risks when ingested. Science of the Total Environment, 2018, 615, P. 141-149.

[105] Sobhanardakani S., Tayebi L., Hosseini S.V. Health risk assessment of arsenic and heavy metals [Cd, Cu Co, Pb, and Sn] through consumption of caviar of Acipenser persicus from Southern Caspian Sea. Environmental Science and Pollution Research, 2018, 25 , P. $2664-2671$.

[106] Darras V., Nelea M., Winnik F.M., Buschmann M.D. Chitosan modified with gadolinium diethylenetriaminepentaacetic acid for magnetic resonance imaging ofDNA/chitosan nanoparticles. Carbohydrate Polymers, 2010, 80, P. 1137-1146.

[107] Surgutskaia N.S., Martino A.D., et al. Efficient $\mathrm{Cu}^{2+}, \mathrm{Pb}^{2+}$ and $\mathrm{Ni}^{2+}$ ion removal from wastewater using electrospun DTPA-modified chitosan/polyethylene oxide nanofibers. Separation and Purification Technology, 2020, 247 (4), 116914.

[108] Lakhdhar I., Mangin P., Chabot B. Copper [II] ions adsorption from aqueous solutions using electrospunchitosan/peo nanofibres: Effects of process variables and process optimization. J. of Water Process Engineering, 2015, 7, P. 295-305.

[109] Bates I.I.C., Loranger É., Chabot B. Chitosan-PEO nanofiber mats for copper removal in aqueous solution using a new versatile electrospinning collector. SN Applied Sciences, 2020, 2, 1540.

[110] Haider S., Park S-Y. Preparation of the electrospun chitosan nanofibers and their applications to the adsorption of $\mathrm{Cu}[\mathrm{II}]$ and $\mathrm{Pb}[\mathrm{II}]$ ions from an aqueous solution. J. of Membrane Science, 2009, 328 (1-2), P. 90-96.

[111] Yang D., Li L., Chen B., Shi S., Nie J., Ma Get al. Functionalized chitosan electrospun nanofiber membranes for heavy-metal removal. Polymer, 2019, 163, P. 74-85.

[112] Castillo J.E.O., Chabot B. Electrospun nanofibers for the removal of heavy metals from aqueous solutions. 2016, Technical Report, Universite du Quebec a Trois-Rivieres. DOI:10.13140/RG.2.2.29893.14569.

[113] Zia Q., Tabassum M., et al. Porous poly[L-lactic acid]/chitosan nanofibres for copper ion adsorption. Carbohydrate Polymers, 2019,227 (12), 115343.

[114] Kokkinos E., Soukakos K., Kostoglou M., Mitrakas M. Cadmium, mercury, and nickel adsorption by tetravalent manganese feroxyhyte: selectivity, kinetic modeling, and thermodynamic study. Environmental Science and Pollution Research, 2018,25 (13), P. 12263-12273.

[115] Mahmoud M.E., El Zokm G.M., Farag A.E., Abdelwahab M.S. Assessment of heat-inactivated marine Aspergillus flavus as a novel biosorbent for removal of $\mathrm{Cd}[\mathrm{II}], \mathrm{Hg}[\mathrm{II}]$, and $\mathrm{Pb}[\mathrm{II}]$ from water. Environmental Science and Pollution Research, 2017, 24, P. 18218-18228.

[116] Petrella A., Spasiano D., et al. Heavy metals retention [Pb[II], Cd[II], Ni[II]] from single and multimetal solutions by natural biosorbents from the olive oil milling operations. Process Safety and Environmental Protection, 2018, 114, P. 79-90.

[117] Alharbi H.F., Haddad M.Y., et al. Electrospun bilayer pan/chitosan nanofiber membranes incorporated with metal oxide nanoparticles for heavy metal ion adsorption. Coatings, 2020, 10 (3), 285.

[118] Brandes R., Belosinschi D., Brouillette F., Chabot B. A new electrospun chitosan/phosphorylated nanocellulose biosorbent for the removal of cadmium ions from aqueous solutions. J. of Environmental Chemical Engineering, 2019, 7 (6), 103477.

[119] Karim M.R., Aijaz M.O., et al. Composite nanofibers membranes of poly[vinyl alcohol]/chitosan forselective lead[II] and cadmium[II] ions removal from wastewater. Ecotoxicology and Environmental Safety, 2019, 169, P. 479-486.

[120] Jamshidifard S., Koushkbaghi S., et al. Incorporation of UiO-66- $\mathrm{NH}_{2}$ MOF into the PAN/chitosan nanofibers for adsorption and membrane filtration of $\mathrm{Pb}(\mathrm{II}), \mathrm{Cd}(\mathrm{II})$ and $\mathrm{Cr}(\mathrm{VI})$ ions from aqueous solutions. J. of Hazardous Materials, 2019, 15 (368), P. 10-20.

[121] Thomas M.S., S. Pillai P.K.S., et al. Polylactic acid/nano chitosan composite fibers and their morphological, physical characterization for the removal of cadmium[II] from water. J. of Applied Polymer Science, 2020, 137 (34), 48993.

[122] Miretzky P., Cirelli A.F. Hg(II) removal from water by chitosan and chitosan derivatives: A review. J. of hazardous materials, 2009 , 167 (13), P. 10-23.

[123] Dorea J.G., Donangelo C.M. Exposure to mercury and aluminum in early life: Developmental vulnerability as a modifying factor in neurologic and immunologic effects. Clinical nutrition, 2006, 25, P. 369-376.

[124] Nolan E.M., Lippard S.J. Tools and tactics for the optical detection of mercuric ion. Chemical reviews, 2008, 108, P. 3443-3480.

[125] Nam K.H., Gomez-Salazar S., Tavlarides L.L. Mercury(II) adsorption from wastewaters using a thiol functional adsorbent. Industrial \& engineering chemistry research, 2003, 42, P. 1955-1964.

[126] Monier M., Ayad D., Wei Y., Sarhan A. Preparation and characterization of magnetic chelating resin based on chitosan for adsorption of $\mathrm{Cu}(\mathrm{II}), \mathrm{Co}(\mathrm{II})$, and Ni(II) ions. Reactive and Functional Polymers, 2010, 70 (4), P. 257-266.

[127] Wu F.C., Tseng R.L., Juang R.S. Kinetic modeling of liquid-phase adsorption of reactive dyes and metal ions on chitosan. Water Research, 2001, 35 (3), P. 613-618.

[128] Pérez-García F., Galán-Vidal C.A., et al. Selective liquid-liquid extraction of mercury(ii) from aqueous solution by N-alkyldithiophosphate compounds $\mathrm{CH}_{3}\left(\mathrm{CH}_{2}\right)_{n} \mathrm{~S}_{2} \mathrm{P}\left(\mathrm{OC}_{6} \mathrm{H}_{4}\right)_{2}(\mathrm{n}=0$ to 4). Separation Science and Technology, 2013, 48, P. 736-740.

[129] Sharma R., Singh N., et al. Cerium functionalized PVA-Chitosan composite nanofibers for effective remediation of ultra-low concentrations of $\mathrm{Hg}[\mathrm{II}]$ in water. RSC Advances, 2015, 5, P. 16622-16630.

[130] Findeiß M.J., Schäffer A. Fate and environmental impact ofthorium residues during rare earth processing. J. of Sustainable Metallurgy, 2017, 3 (2), P. 179-189.

[131] Gore P.M., Khurana L., et al. Ion-imprinted electrospun nanofibers of chitosan/1-butyl-3-methylimidazolium tetrafluoroborate for the dynamic expulsion of thorium (IV) ions from mimicked effluents. Environmental Science and Pollution Research, 2018, 25, P. 3320-3334. 
[132] Martins M., Faleiro M.L., et al. Anaerobic bio-removal of uranium (VI) and chromium (VI): comparison of microbial community structure. J. of Hazardous Materials, 2010, 176 (1-3), P. 1065-1072.

[133] Villalobos-Rodriguez R., Montero-Cabrera M.E., et al. Uranium removal from water using cellulose triacetate membranes added with activated carbon. Applied Radiation and Isotopes, 2012, 70 (5), P. 872-881.

[134] Aly M.M., Hamza M.F. A review: Studies on uranium removal using differenttechniques. Overview. J. of Dispersion Science and Technology, 2013, 34 (2), P. 182-213.

[135] Bhalara P.D., Punetha D., Balasubramanian K. A review of potential remediation techniques for uranium[VI] ionretrieval from contaminated aqueous environment. J. of Environmental Chemical Engineering, 2014, 2, P. 1621-1634.

[136] Christou C., Philippou K., Krasia-Christoforou T., Pashalidis I. Uranium adsorption by polyvinylpyrrolidone/chitosan blended nanofibers. Carbohydarte polymers, 2019, 219, P. 298-305.

[137] Keshtkar A.R., Irani M., Moosavian M.A. Removal of uranium (VI) from aqueous solutions by adsorption using a novel electrospun PVA/TEOS/APTES hybrid nanofiber membrane: comparison with casting PVA/TEOS/APTES hybrid membrane. J. of Radioanalytical and Nuclear Chemistry, 2013, 295, P. 563-5571.

[138] Rastmanesh F., Safaie S., Zarasvandi A.R., Edraki M. Heavy metal enrichment and ecological risk assessment of surface sediments in Khorramabad River, West Iran. Environmental Monitoring and Assessment, 2018, 190 (5), 273.

[139] Biglari H., Saeidi M.,et al. Review on hydrochemical and health effects of it in Sistan and Baluchistan groundwaters Iran. Int. J. of Pharmacy and Technology, 2016, 8 (3), P. 17900-17920.

[140] Goel P.K. Water pollution: Causes, effects and control. New Age International, New Delhi, 2006.

[141] Genchi G., Carocci A., et al. Nickel: Human Health and Environmental Toxicology. Int. J. of Environmental Research and Public Health, $2020,17,679$.

[142] Karamipour A., Khadiv-Parsi P., et al. Using $\mathrm{Fe}_{3} \mathrm{O}_{4}$-coated nanofibers based on cellulose acetate/chitosan for adsorption of Cr[VI], Ni[II] and phenol from aqueous solutions. Int. J. of Biological Macromolecules, 2019, 154, P. 1132-1139.

[143] Bozorgi M., Abbasizadeh S., Samani F., Mousavi S.E. Performance of synthesized cast and electrospun PVA/chitosan/ZnO-NH 2 nanoadsorbents in single and simultaneous adsorption of cadmium and nickel ions from wastewater. Environmental Science and Pollution Research, 2018, 25, P. 17457-17472.

[144] Habiba U., Afifi A.M., Salleh A., Ang B.C. Chitosan/[polyvinyl alcohol]/zeolite electrospun composite nanofibrous membrane for adsorption of $\mathrm{Cr}^{6+}, \mathrm{Fe}^{3+}$ and $\mathrm{Ni}^{2+}$. J. of Hazardous Materials, 2016, 322, P. 182-194.

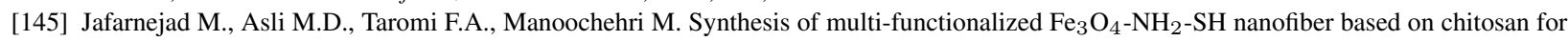
single and simultaneous adsorption of $\mathrm{Pb}[\mathrm{II}]$ and $\mathrm{Ni}[\mathrm{II}]$ from aqueous system. Int. J. of Biological Macromolecules, $2020,148, \mathrm{P} .201-217$.

[146] Min L-L., Yuan Z-H., et al. Preparation of chitosan based electro spun nanofiber membrane and its adsorptive removal of arsenate from aqueous solution. Chemical Engineering Journal, 2014, 267, P. 132-141.

[147] Tan P., Zheng Y., Hub Y. Efficient removal of arsenate from water by lanthanum immobilized electrospun chitosan nanofiber. Colloids and Surfaces A: Physicochemical and Engineering Aspects, 2020, 589, 124417.

[148] Min L-L., Yang L-M., et al. Enhanced adsorption of arsenite from aqueous solution by an iron-doped electro spun chitosan nanofiber mat: Preparation, characterization and performance. J. of Colloid and Interface Science, 2019, 535, P. 255-264.

[149] Sharma R., Singh N., et al. Electro spun chitosan-polyvinyl alcohol composite nanofibers loaded with cerium for efficient removal of arsenic from contaminated water. J. of Material Chemistry A, 2014, 2, P. 16669-16677.

[150] Min L-L., Zhong L-B., et al. Functionalized chitosan electro spun nanofiber for effective removal of trace arsenate from water. Scientific Reports, 2016, 6, 32480.

[151] Li L., Li Y., Yang C. Chemical filtration of Cr (VI) with electrospun chitosan nanofiber membranes. Carbohydrate Polymers, 2016, 140, P. 299-307.

[152] Aliabadi M., Irani M., et al. Electrospun nanofiber membrane of PEO/Chitosan for the adsorption of nickel, cadmium, lead and copper ions from aqueous solution. Chemical Engineering Journal, 2013, 220, P. 237-243.

[153] Li X., Zhou H., et al. Studies of heavy metal ion adsorption on chitosan/sulfydryl-functionalized graphene oxide composites. J. of Colloid and Interface Science, 2015, 448, P. 389-397.

[154] Karthik R., Meenakshi S. Removal of $\mathrm{Pb}(\mathrm{II})$ and $\mathrm{Cd}(\mathrm{II})$ ions from aqueous solution using polyaniline grafted chitosan. Chemical Engineering Journal, 2015, 263, P. 168-177.

[155] Chen A.H., Liu S.C., Chen C.Y., Chen C.Y. Comparative adsorption of $\mathrm{Cu}[\mathrm{II}], \mathrm{Zn}[\mathrm{II}]$, and Pb[II] ions in aqueous solution on the crosslinked chitosan with epichlorohydrin. J. of Hazardous materials, 2008, 154 (1), P. 184-191.

[156] Phan D-N., Lee H., et al. Fabrication of electrospun chitosan/cellulose nanofibers having adsorption property with enhanced mechanical property. Cellulose, 2019, 26, P. 1781-1793.

[157] Zhang X., Shi X., et al. Preparation of chitosan stacking membranes for adsorption of copper ions. Polymers, $2019,11,1463$.

[158] Boddu V.M., Abburi K., et al. Removal of arsenic [III] and arsenic [V] from aqueous medium using chitosan-coated biosorbent. Water Research, 2008, 42 (3), P. 633-642.

[159] Guo X., Du B., et al. Synthesis of amino functionalized magnetic graphenes composite material and its application to remove Cr(VI), $\mathrm{Pb}$ (II), $\mathrm{Hg}(\mathrm{II}), \mathrm{Cd}(\mathrm{II})$ and $\mathrm{Ni}(\mathrm{II})$ from contaminated water. J. of Hazardous Materials, 2014, 278, P. 211-220.

[160] Li J., Jiang B., et al. Preparation and adsorption properties of magnetic chitosan composite adsorbent for Cu ${ }^{2+}$ removal. J. of Cleaner Production, 2017, 158, P. 51-58.

[161] Mahfouz M.G., Galhoum A.A., et al. Uranium extraction using magnetic nano-based particles of diethylenetriamine-functionalized chitosan: Equilibrium and kinetic studies. Chemical Engineering Journal, 2015, 262, P. 198-209.

[162] Shariful M.I., Sepehr T., et al. Adsorption capability of heavy metals by chitosan/poly (ethylene oxide)/activated carbon electrospun nanofibrous membrane. J. of Applied Polymer Science, 2017, 135, 45851.

[163] Min M., Shen L., et al. Micro-nano structure poly(ether sulfones)/poly(ethyleneimine) nanofibrous affinity membranes for adsorption of anionic dyes and heavy metal ions in aqueous solution. Chemical Engineering Journal, 2012, 197, P. 88-100. 